Article

\title{
Why Pandemics, Such as COVID-19, Require a Metropolitan Response
}

\author{
Shlomo Angel * and Alejandro Blei
}

Citation: Angel, S.; Blei, A. Why Pandemics, Such as COVID-19, Require a Metropolitan Response. Sustainability 2021, 13, 79.

https://doi.org/10.3390/su13010079

Received: 3 November 2020 Accepted: 18 December 2020 Published: 23 December 2020

Publisher's Note: MDPI stays neutral with regard to jurisdictional clai$\mathrm{ms}$ in published maps and institutional affiliations.

Copyright: (C) 2020 by the authors. Licensee MDPI, Basel, Switzerland. This article is an open access article distributed under the terms and conditions of the Creative Commons Attribution (CC BY) license (https:// creativecommons.org/licenses/by/ $4.0 /)$.
Marron Institute of Urban Management, New York University, New York, NY 10011, USA; ablei@stern.nyu.edu * Correspondence: sangel@stern.nyu.edu

\begin{abstract}
We introduce evidence from the COVID-19 pandemic in the United States that lends support to future political efforts to include multi-county metropolitan areas as an additional and critical institutional layer-over and above municipalities, countries, states, or the federal governmentfor the effective management of present and future pandemics. Multi-county metropolitan statistical areas (MSAs) accommodated 73\% of the U.S. population and, as of 27 September 2020, they were home to $78 \%$ of reported cases of COVID-19 and $82 \%$ of reported deaths. The rationale for a renewed focus on these spatial units is that they are found to be densely interconnected yet easily identifiable locales for the spread of pandemics and, therefore, for their proper management as well. The paper uses available data on cases and deaths in U.S. counties as of 27 September 2020 to lend statistical support to four hypotheses: (1) The Onset Hypothesis: The onset of COVID-19 cases and deaths commenced earlier in multi-county metropolitan areas than in small-city counties or rural counties; (2) The Peak Hypothesis: The current peak of COVID-19 cases and deaths occurred earlier in multi-county metropolitan areas; (3) The Scaling Hypothesis: Multi-county metropolitan areas had more than their shares of COVID-19 cases and deaths than their shares in the population; and (4) The Neighbor Hypothesis: Levels of COVID-19 cases and deaths in counties within multicounty metropolitan areas were more strongly related to respective levels in their neighboring counties than small-city counties or rural counties. The reported statistical results demonstrate the value of adopting a metropolitan perspective on pandemics and working to empower effective institutional arrangements at the metropolitan level for managing the present and future pandemics.
\end{abstract}

Keywords: COVID-19; metropolitan governance; pandemics; U.S. counties; metropolitan statistical areas

\section{Introduction: A Sharper Focus on Multi-County Metropolitan Areas}

The COVID-19 pandemic has by now spread over the entire United States. As of 27 September 2020, for example, 3112 out of a total of 3142 counties-accommodating $99.98 \%$ of the total population of the country-recorded cases of people infected by the virus, and 2441 out of a total of 3142 counties-accommodating $97.64 \%$ of the total population-recorded deaths from the virus.

The question of interest to us is 'how did the virus spread across the United States?' More specifically, we are interested in the role that large multi-county metropolitan areas played in the spread of the pandemic. Almost three-quarters of the U.S. population now inhabits multi-county metropolitan areas, large agglomerations that function as single integrated economies with broad global reach, drawing on vast economies of scale that come from high levels of their internal interconnectedness. It is the high density of connections within these large economic units that lends them such economic advantages: All firms have access to all workers and all workers have access to all jobs; there are large markets that enable specializations, vast opportunities for learning and innovation, strong connections to global markets, easier replacement of dying firms, and higher levels of amenities attracting both creative people and visitors from abroad. It is precisely those advantages, and the spatial interactions they entail—in public and commercial buildings, 
on transport networks, and in public and private spaces, among others-that make these multi-county metropolitan agglomerations vulnerable to pandemics, especially during their early stages, when their 'urban health penalty' [1] is at its highest while its 'urban health advantage,' if indeed there is one, has not yet manifested itself. By 27 September 2020, for example, eight months into the current pandemic, no less than $78 \%$ of all confirmed COVID-19 cases and $81 \%$ of all deaths were found in multi-county metropolitan areas.

Several insights from geographic theory offer a path for investigating the spread of the COVID-19 pandemic in the United States in general and in its multi-county metropolitan areas in particular. Geographic theory suggests that (1) larger cities and metropolitan areas are more globalized and more interconnected with each other than smaller cities, towns, and villages [2-6]; (2) there is a hierarchy of 'central places' connecting villages to small towns, towns to smaller cities, smaller cities to larger ones, and larger cities to metropolitan areas [7,8]; (3) human settlements obey scaling laws, where larger settlements have more than their share of some attributes-pandemic volume and more specialized healthcare services included-than smaller places [9-11]; (4) multi-county metropolitan areas form single, integrated, and densely connected metropolitan labor markets [12]; and (5) "everything is related to everything else, but near things are more related than distant things", known as Tobler's First Law of Geography [13].

Our main interest in this paper, as we noted above, is in larger cities and metropolitan areas, which in the United States typically encompass several counties. Given the theoretical observations summarized above, we can posit four hypotheses pertaining to the geographic spread of the Coronavirus in the United States that focus on multi-county metropolitan areas:

The Onset Hypothesis (Hypothesis 1). The onset of COVID-19 cases and deaths commenced earlier in multi-county metropolitan areas than in small-city counties, and earlier in small-city counties than in rural areas;

The Peak Hypothesis (Hypothesis 2). The current peak of COVID-19 cases and deaths occurred earlier in multi-county metropolitan areas than in small-city counties, and earlier in small-city counties than in rural areas;

The Scaling Hypothesis (Hypothesis 3). The incidence of COVID-19 cases and deaths was proportionally greater than differences in population among multi-county metropolitan areas and small cities/rural areas, or more generally, between more populous and less populous counties.

The Neighbor Hypothesis (Hypothesis 4). Levels of COVID-19 cases and deaths in counties within multi-county metropolitan areas were more strongly related to respective levels in their neighboring counties than small-city counties or rural counties.

In the body of this paper, we present evidence that supports these hypotheses or, more precisely, affirms the high statistical likelihood that these hypotheses cannot be rejected. The primary data we use to construct the statistical evidence is the daily number of reported COVID-19 cases and deaths in all 3142 U.S. counties for more than 8 months, from 21 January 2020 to 27 September 2020.

The reader may ask a legitimate question: Does this knowledge matter? Does it have any policy implications? We believe it does. Data on the pandemic is reported daily for single counties and states, but not for multi-county metropolitan areas. If indeed, as we shall demonstrate below, multi-county metropolitan areas act as integrated locales for the spread of the virus, then this calls for coordinated policies-say those concerning the closure and gradual opening of businesses or schools or those mandating the coordination of testing and hospitalizations-for these locales. If neighboring metropolitan counties indeed infect each other, then such policies are likely to be more successful than single-county policies or than statewide policies, considering that many multi-county metropolitan areas cross state lines (there are 46 multi-county metropolitan statistical areas (MSAs) (12\% of the total of 384 MSAs and $20 \%$ of the 235 multi-county MSAs) that have counties in more than one 
state. These 46 MSAs contain 77.5 million people, $28 \%$ of the total population of MSAs, and $24 \%$ of the total population of the U.S.) and that states contain a rich mix of rural and urban counties that are quite different and disassociated from each other.

Our main policy recommendation then-addressed to federal, state, county, and municipal authorities - is that they need to formulate and implement public health policies pertaining to the pandemic that are specifically tailored to multi-county (and, needless to say, multi-municipality) metropolitan areas. These are not states nor counties, yet they require a coordinated metropolitan response, a response that calls for an appropriate governmental structure-in the case of rapidly-spreading pandemics, given the urgency, possibly a powerful metropolitan commission - that can plan in advance and deliver such a response effectively in a timely manner. Not surprisingly, such a commission was recommended by Burlage [14] for the New York metropolitan area more than 50 years ago (Burlage argued, however, that affiliations as currently practiced were inherently exploitative and unaccountable. His institutional critique denounced "too much uncontrolled domination by the scattered 'private' and 'academic' sectors of health services" ([14] (p. 262), quoted in [15]) With respect to policy, it called for the creation of a centralized public Metropolitan Health Services Commission that would regulate the municipal hospitals [14] (pp. 515-520) and to no avail.

What effective metropolitan coordination should look like raises the questions of how to appropriately define metropolitan areas and how to leverage overlapping governance structures to pursue pandemic related goals. Our focus in this paper is the U.S. context, but the geographic scale of the COVID-19 pandemic now makes these highly relevant questions for cities worldwide. On the matter of metropolitan area definition, it is generally understood that they encompass a central city or cities, and their commuting areas, thus approximating a functional urban area as opposed to an area based on political or administrative considerations alone [16]. The building blocks of these functional areas are typically nested jurisdictional or administrative zones. This ensures linkages with respect to governance, administration, and statistical reporting in the larger area. In the U.S., the smaller zones correspond to counties, which are the second subnational administrative division below states. While there are much smaller geographic divisions within the U.S. statistical reporting system, metropolitan commuting is measured by flows aggregated at the county level, making them the building block of census defined Metropolitan Statistical Areas [17]. European Union and OECD countries apply a similar functional urban area definition based on city centers and commuting thresholds between local administrative units [18]. In many countries, however, the underlying data necessary to define functional urban area boundaries do not exist or the existing data is not compatible with prevailing measurement approaches. Efforts to develop a standardized definition of metropolitan areas using population grids, satellite imagery, and commuting data are underway and may be applied in relevant situations [16].

How to improve the effectiveness of policy formulation and implementation across metropolitan areas calls into question issues of multilevel governance. In a sense, the pandemic has produced a type of natural experiment with respect to different governance models and their ability to respond to various challenges. Coordination of national and local governments for the financing of testing and supplies, for responding to employment shocks, or for local revenue compensation, was important to lay the foundation for sustainable responses in places such as Germany or China [19]. In the U.S., where such coordination was less robust, cities and states pursued more of a go-it-alone strategy without guarantees of direct assistance from the federal government.

As of 2020, there were very few multi-county public health departments in the U.S., and only a few states had regional public health departments that spanned several counties. A coordinated multi-county metropolitan-wide approach to public health crises was completely passed over, for example, in the post 9/11 recommendations for massive reforms of the U.S. public health system needed to make it more resilient to crises [20]. We note in passing that New York City-which is made up of five counties-is the only multi-county 
urban entity in the U.S. with a single public health department, but even New York City with its 8.3 million people in 2018 is only a small part of the 22-county New York-NewarkJersey City Metropolitan Statistical Area (MSA), which contained more than 19.3 million people in that year. Reference to 'metropolitan' health departments other than New York City in the U.S. typically refers to large single-county jurisdictions, not to multi-county metropolitan statistical areas (MSAs) (see, e.g., Reference [21]).

Metropolitan Planning Organizations (MPOs) - mandated by the Federal Aid Highway Act of 1962 as a precondition for receiving federal transportation funds-are still largely restricted to transportation and land use planning and not to the management of responses to public health crises, even though they occasionally identify public health as an important transportation objective [22] (pp. 94 and 99). Portland Metro, for example, the only elected multi-county and multi-municipality metropolitan government in the country other than New York City, has powerful responsibilities for planning and governance at the metropolitan scale, but managing public health crises at the metropolitan scale is not one of them [23] The South Coast Air Quality Management District, to take another example, has an effective multi-county governing board that monitors and enforces air quality standards in the Los Angeles basin, but it is restricted to air quality management from stationary sources [24].

There have been numerous urgent calls to confront pandemics at the metropolitan scale. Keil and Ali, for example, forcefully "argue that urban governance must face the new (or reemerging) challenge of dealing with infectious disease in the context of the "new normal" and that global health governance may be better off by taking the possibilities that rest in metropolitan governance more seriously [25] (p. 846). Their work is based on the analysis of the impact of the SARS epidemic in 2003 on Toronto, Canada, as well as on numerous studies that have noted the loss of clear boundaries among municipal, provincial, and state jurisdictions and the emergence of "metropolitanization" [26]. They conclude that "both concepts—city and state-are becoming perforated as the "institutional void" around emerging infectious disease corrodes firm boundaries between jurisdictional responsibilities of territorial states and city regions." [25] (p. 867).

During the current pandemic, in our humble assessment, it is only because largely uncoordinated and often contradictory federal, state, and municipal actions involving closures and 'social distancing' were able to 'flatten the curve' in time that the highly privatized and highly fragmented healthcare systems in U.S. metropolitan areas were able to handle COVID-19 related hospitalizations, to take one example, with minor to non-existent public sector coordination. Efforts at metropolitan coordination in the tristate area by the governors of New York, New Jersey, and Connecticut may have been a modest anecdotal exception, with important results in 'flattening the curve' in the New York metropolitan area in a relatively short time. That was a close call. As a matter of public health policy, or public policy in general, such a level of unpreparedness at the metropolitan scale is clearly unacceptable.

The data analyzed in the following sections in support of the four hypotheses outlined above provide, for the first time, some of the scientific evidence needed to, at the very least, generate some interest in academic and political circles in fashioning a multi-county metropolitan response- rather than a county-based or state-based response- to public health crises such as the current COVID-19 pandemic.

\section{Methodology and Data}

U.S. counties are the smallest spatial unit for which information on COVID-19 cases and deaths is available nationwide on a daily basis. There is no official source of agglomerated, nationwide, daily COVID-19 county data, however, and the available data is largely from the unofficial agglomeration of official reporting. While the Center for Disease Control and Prevention (CDC) reports on state cases and deaths using the information provided by relevant state authorities, it relies on a non-governmental civic initiative for its case and death data for individual counties (the CDC webpage for cases and deaths by 
county relies on information collected by the organization USA Facts, www.usafacts.org). Non-government organizations-including USA Facts, Johns Hopkins University, and The New York Times-produce nationwide county-level time-series datasets that are publicly available for download. The underlying sources of each organization's data are largely the same-information contained in state or county health department websites-but comparisons of the case and death counts across datasets may sometimes show county-level inconsistencies on a given day. Procedures unique to each organization's data collection, review, and editing processes likely play a role in explaining these differences. To our knowledge, a detailed review of differences across datasets does not exist and further analysis is needed to understand how a particular dataset may bias county-level analysis.

Our analysis used The New York Times county-level dataset that is available for download on its COVID-19 Data Github webpage. This decision was based on its ease of use and a review and comparison of its methodology and documentation procedures. The case and death data in our analysis cover the period beginning on 21 January 2020, when there was one confirmed case in Snohomish County, Washington, through 27 September 2020, when there were over 5.8 million cases in 3112 counties ( 99 percent of counties) and over 176,000 deaths in 2441 counties (78 percent of counties).

The New York Times COVID-19 dataset contains information for counties only if they have associated cases or deaths. To create a nationwide dataset with information for all counties, including those with no cases or no deaths, we used county Federal Information Processing Standards (FIPS) codes to join The New York Times data to a file of 3142 counties downloaded from the Census Bureau's Cartographic Boundary File webpage. Combined, the 3142 counties comprise all areas in the 50 states and the District of Columbia. We also joined information for county population data using American Community Survey estimates for 2014-2018, the most recent 5-year estimate period, as well as information for the amount of impervious surface (built-up area) within counties, using data from the National Land Cover Database.

Counties were subsequently assigned codes corresponding to their core-based statistical area (CBSA) or were labeled rural counties. CBSAs refer to metropolitan and micropolitan statistical areas. The abbreviation MSA is commonly used in place of the lengthier 'metropolitan statistical area' but there is no equivalent three-letter abbreviation for micropolitan areas. Both terms refer to sets of counties anchored by densely settled urban areas where the counties are linked together by commuting patterns. These areas are defined by the U.S. Office of Management and Budget and updated every 10 years to reflect evolving population and commuting dynamics. The key difference between metropolitan and micropolitan areas concerns the size of the core urban area population used to define them: between 10,000-50,000 for micropolitan areas and above 50,000 for metropolitan areas. In practice, CBSAs may contain as few as one county or as many as 29 . They exist primarily as a reference for comparative statistical reporting on economic and social data.

Figure 1 shows the fourteen-county, three-state area comprising the Chicago-NapervilleElgin metropolitan statistical area, more commonly referred to as the Chicago MSA. CBSA naming rules allow for the inclusion of up to three principal cities (municipal jurisdictions) within the MSA based on population and employment criteria. The urbanized area within the MSA represents a relatively contiguous densely settled built-up area. Its area may provide a more accurate representation of what is colloquially understood to represent the principal city's metropolitan area. 


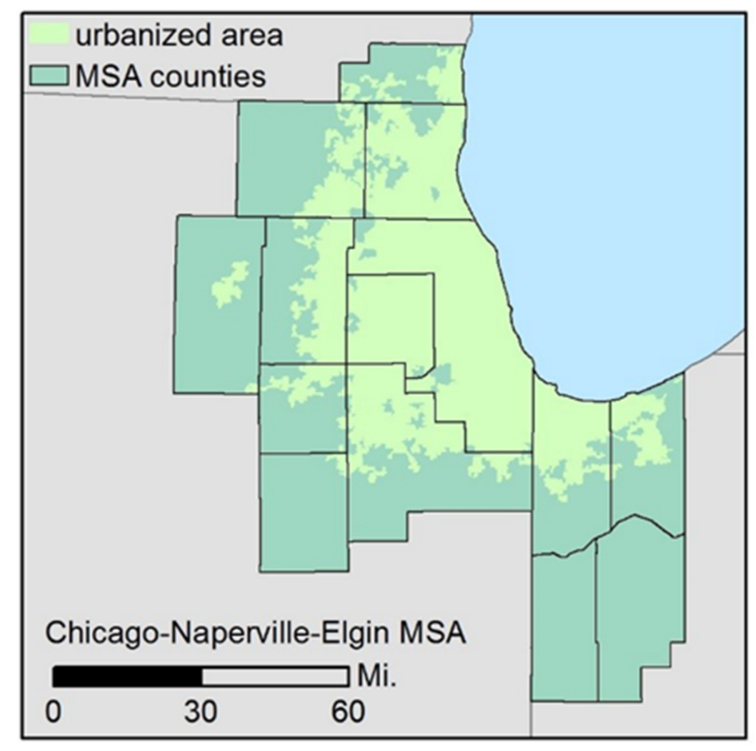

Figure 1. The Chicago-Naperville-Elgin Metropolitan Statistical Area (MSA) spans three statesWisconsin, Illinois, and Indiana-and contains 14 counties and 287 incorporated municipalities.

\subsection{Attributes of Multi-County MSAs, Small Cities, and Rural Counties}

We assigned all counties in the U.S. into one of three categories: (1) multi-county MSAs, or counties belonging to MSAs comprising at least two counties; (2) small cities, or counties belonging either to single county MSAs or micropolitan statistical areas, whether they comprised one or multiple counties; and (3) rural counties, or counties that were neither metropolitan nor micropolitan area counties, namely counties that were not anchored by a densely settled urban core of at least 10,000 inhabitants. Table 1 contains summary information for the three categories of counties and a combined measure for all counties. There were 1029 counties in multi-county MSAs, 805 counties in small cities, and 1308 rural counties. Multi-county MSAs represented only one-third of all counties but housed 73 percent of the U.S. population. The share of counties in the rural category was the largest (41 percent) but contained only 6 percent of the country's population. The average population size of counties in the three categories were all significantly different from each other: counties in multi-county MSAs and small cities had average populations of 223,108 and 92,426, respectively, while rural counties had average populations of 13,879 .

The map in Figure 2 shows the geographic distribution of multi-county MSAs, small cities, and rural counties across the United States. We highlight the distinction between single county MSAs (dark yellow) and counties in micropolitan areas (light yellow) within the small cities category. Although multi-county MSAs can be found in every U.S. region, they appear concentrated in the central and eastern half of the country, a pattern that reflects the overall distribution of population nationwide. The map would also appear to show that the size of counties in the central and eastern portions of the U.S. are, on average, smaller than those further west. The thin black border that surrounds individual multi-county MSAs in Figure 2 is absent from multi-county micropolitan areas to increase map legibility. Of 542 micropolitan areas, 83 percent comprised one county only.

Overall, there were 235 multi-county metropolitan statistical areas in 2020. While their average population was 1 million, their populations varied considerably, from a minimum of 62,500 in Lewiston, ID-WA, to a maximum of 19.3 million in New York-Newark-Jersey City MSA in NY-NJ. Figure 3 focuses on the number of multi-county MSAs in different population range categories. In general, the higher the population range, the fewer the number of multi-county MSAs within it. The pattern of ascending bars as population ranges decrease does not extend to the lowest population range, 50,000-100,000 in part because the data has been trimmed to exclude one-county MSAs. 
Table 1. Attributes of counties classified along three categories: counties in multi-county MSAs, small cities, and rural counties.

\begin{tabular}{|c|c|c|c|c|c|}
\hline & & All Counties & Multi-County MSAs & Small Cities & Rural Counties \\
\hline \multirow[t]{2}{*}{ Count } & & 3142 & 1029 & 805 & 1308 \\
\hline & $\%$ of Total & $100 \%$ & $33 \%$ & $26 \%$ & $42 \%$ \\
\hline \multirow[t]{6}{*}{ Population } & & $322,538,482$ & $235,411,538$ & $69,006,072$ & $18,120,872$ \\
\hline & $\%$ of Total & $100 \%$ & $73 \%$ & $21 \%$ & $6 \%$ \\
\hline & Average & 101,121 & 223,108 & 92,426 & 13,879 \\
\hline & Median & 25,629 & 76,232 & 43,961 & 10,973 \\
\hline & IQR & $10,832-67,288$ & $26,868-211,579$ & $27,174-79,609$ & $5782-18,856$ \\
\hline & $\widehat{S D}$ & 330,774 & 529,221 & 186,318 & 11,371 \\
\hline \multirow[t]{6}{*}{$\operatorname{Area}\left(\mathrm{km}^{2}\right)$} & & $9,347,450$ & $1,907,766$ & $2,605,785$ & $4,834,368$ \\
\hline & $\%$ of Total & $100 \%$ & $20 \%$ & $28 \%$ & $52 \%$ \\
\hline & Average & 2975 & 1854 & 3237 & 3696 \\
\hline & Median & 1635 & 1409 & 1836 & 1830 \\
\hline & IQR & $1137-2454$ & 974-1951 & $1267-2920$ & $1255-2675$ \\
\hline & $\hat{\mathrm{SD}}$ & 9533 & 3159 & 4612 & 13993 \\
\hline
\end{tabular}

Distance to Neighboring

Counties $(\mathrm{km})$

$\begin{array}{lrrrr}\text { Average } & 55 & 40 & 60 & 63 \\ \text { Median } & 47 & 39 & 50 & 51 \\ \text { IQR } & 38-58 & 33-47 & 42-64 & 43-66 \\ 95 \% \text { CI } & 53-56 & 39-41 & 57-62 & 60-65\end{array}$

Gross Density (persons $/ \mathrm{km}^{2}$ )

$\begin{array}{lrrrr}\text { Average } & 96 & 249 & 39 & 11 \\ \text { Median } & 17 & 56 & 24 & 7 \\ \text { IQR } & 6-44 & 22-162 & 12-44 & 2-14 \\ 95 \% \text { CI } & 77-115 & 191-306 & 35-43 & 9-13\end{array}$

Built-up Density (persons $/ \mathrm{km}^{2}$ )

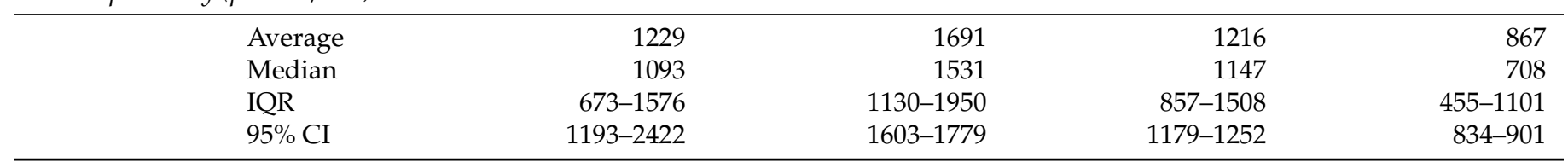

Figure 4 complements Figure 3, showing the share of the total population in multicounty MSAs in each population size range. Here, the general pattern in Figure 3 is somewhat reversed. As the population ranges increase, we observe a greater share of the total population in that range. Again, this is not entirely true for the entire range: The two highest population ranges contain a smaller share of the total multi-county MSA population than several preceding ranges. In short, counties in multi-county MSAs, while more populous than small-city counties or rural counties, are also integral parts of much more populous urban agglomerations. 


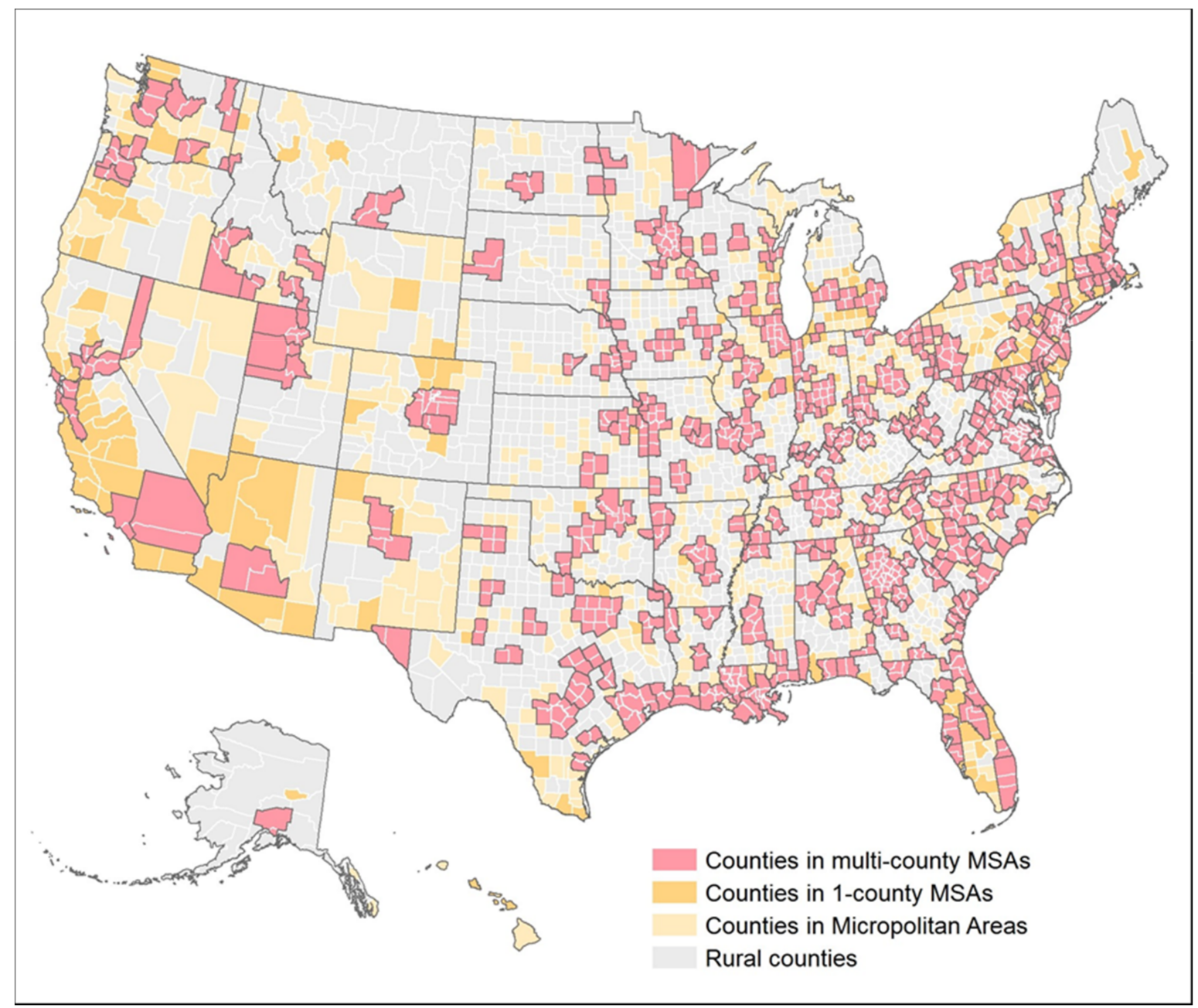

Figure 2. A map of the United States showing counties in multi-county MSAs, counties with small cities (single-county MSAs and Micropolitan area counties), and rural counties.

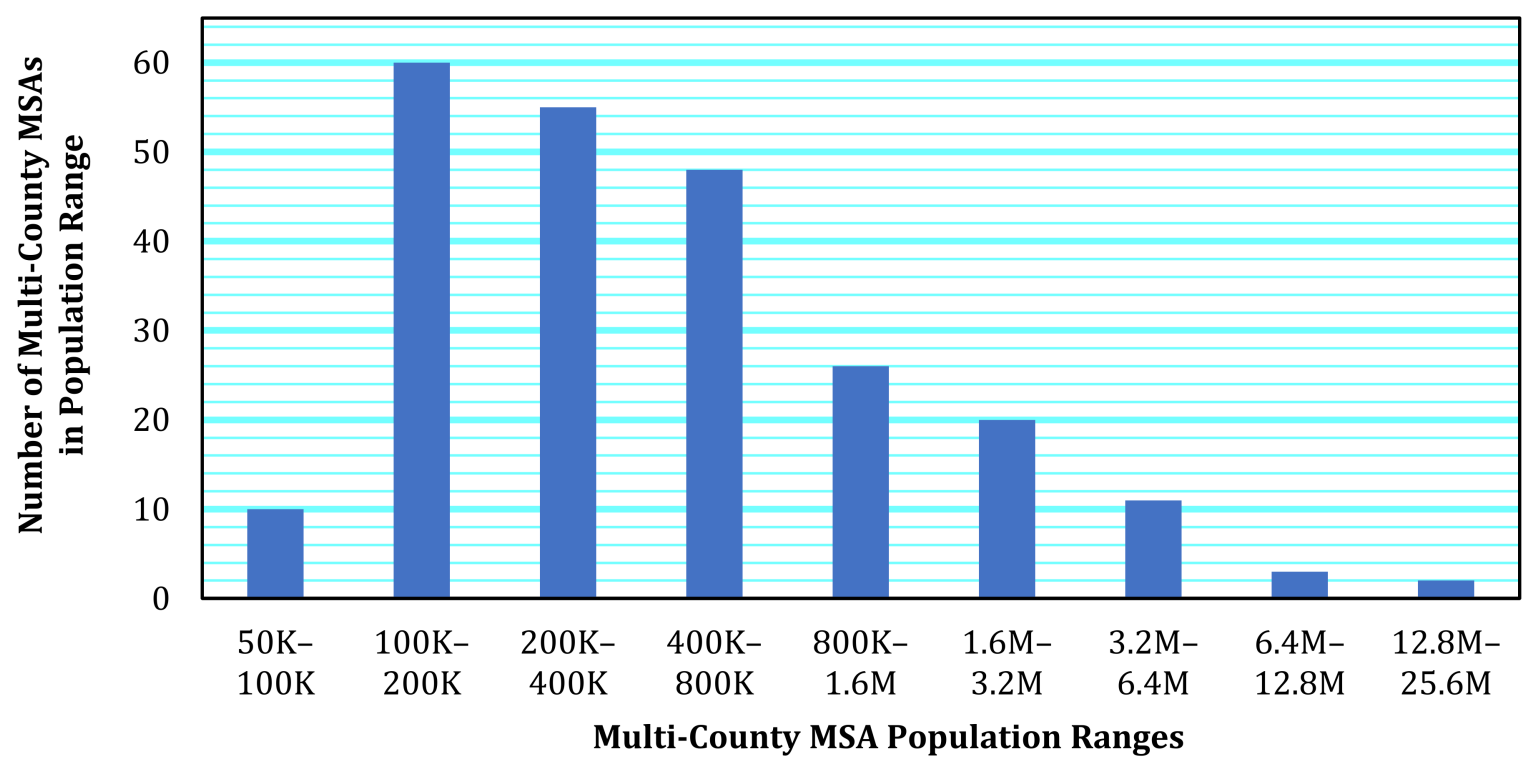

Figure 3. The distribution of the number of multi-county MSAs by population range. 


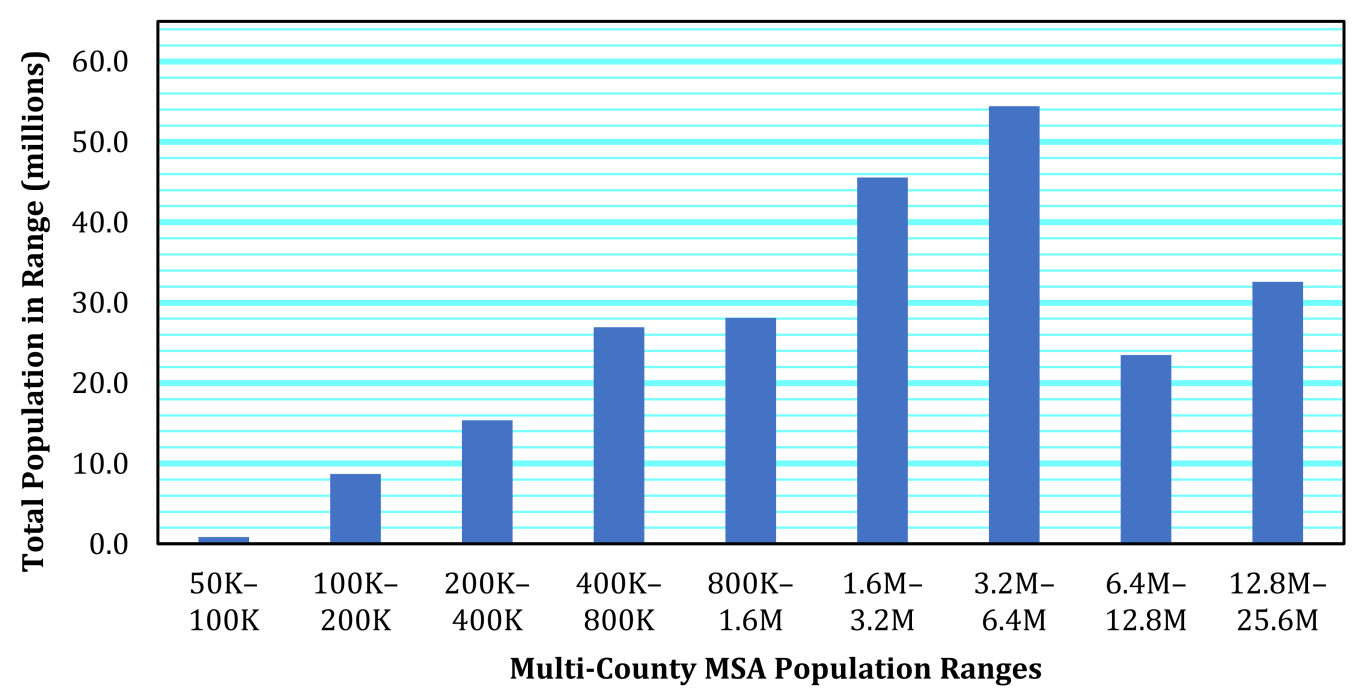

Figure 4. The distribution of the total population in multi-county MSAs in each population range.

Beyond differences in their average populations, counties in multi-county MSAs, small-city counties, and rural counties also varied in the area (see Table 1). Counties in multicounty MSA were the smallest, with an average size of $1854 \mathrm{~km}^{2}$. This was significantly smaller than the average size of small-city counties $\left(3237 \mathrm{~km}^{2}\right)$ or rural counties $\left(3696 \mathrm{~km}^{2}\right)$, though the size difference between these last two categories was not statistically significant. We also calculated the average distance to a county's neighbors across these three categories. A county neighbor is one that shares a common boundary (for the neighbor analysis, a neighboring county can include a county in a different category, i.e., a rural county can have a neighbor in a multi-county MSA). Average distances were calculated using the population-weighted centroids of counties, where county centroids were calculated using the populations and geographic centroids of census tracts within them. For counties in multi-county MSAs, the average distance to neighbors was the smallest, $40 \mathrm{~km}$. This was significantly smaller than the average distance to neighbors in small-city counties $(60 \mathrm{~km})$ or rural counties $(63 \mathrm{~km})$, though the difference between these last two categories was not statistically significant.

Differences in population and area among the three county categories translated into differences in population density as well (Table 1). The population density was calculated as the ratio between the total population of a county and its area. We used two area measures: the gross area of a county and the built-up area of the county, the latter calculated using information from the National Land Cover Database. Density differences across the three categories were significant whether we used a county's gross area or built-up area in the denominator. The built-up area metric is more meaningful, however, since it normalizes gross areal differences, focusing only on areas related to human activity and settlement. Counties in multi-county MSAs had the highest average densities, followed by small-city counties, followed by rural counties, and these averages were all significantly different from each other. Using the built-up area metric, counties in multi-county MSAs were approximately 30 percent denser than small-city counties and approximately 100 percent denser than rural counties.

\subsection{The Calculation of Case and Death Metrics in Counties and Their Neighbors}

The New York Times COVID-19 dataset reports cumulative case and death counts for individual counties by day. Our analyses of the scaling and neighbor hypotheses make use of these raw cumulative values. Our analyses of the onset, peak, and neighbor hypotheses also required information on new cases and deaths per day. We calculated new cases/deaths per day by first computing the incremental daily change in cases/deaths. We then smoothed the data with a seven-day average: we averaged the incremental values of the six preceding days and the incremental value on the day in question. 
Peak values and dates for cases and deaths were identified as the maximum values of these seven-day averages, subject to two conditions: First, that counties with zero values had no peak; and second, that the peak value was maintained for two weeks by 27 September 2020. In other words, counties that had maximum values less than two weeks before 27 September 2020 or, for that matter, on 27 September 2020, were not considered to have attained their peak values. It is important to note that the pandemic may have several peaks as time goes by, so the peaks we have identified can only be considered the 'current' peaks or the 'latest' peaks. A single peak for each county can only be identified once the pandemic is over.

The Neighbor Hypothesis analysis required the comparison of dates associated with the onset and peak, and a comparison of cumulative cases and deaths per 100,000 people on 27 September 2020 for counties and their neighbors. Average dates of neighbors were calculated by weighing neighbor dates by their populations. Average values of neighbors were calculated by computing neighbors' values per 100,000 and weighing these normalized measures by their populations.

In the following four sections, we discuss our analyses of the onset, peak, scaling, and neighbor hypotheses pertaining to the geographic spread of COVID-19. While the analyses are fundamentally county-based, they are presented through the lens of the three categories described above: counties belonging to multi-county MSAs, small-city counties, and rural counties. Among these groups, we explore measures of incidence and temporality by (1) comparing average values, (2) comparing differences between counties and their neighbors, and (3) comparing correlations between counties and their neighbors.

\section{The Onset Hypothesis}

The onset of COVID-19 cases and deaths commenced earlier in multi-county metropolitan areas than in small-city counties, and earlier in small-city counties than in rural areas.

There is a large body of literature that views the international global network of cities, linked with each other in a dense network of airline connections and electronic communications, housing global elites, and exchanging both goods and services as well as tourist amenities, as a key feature of contemporary globalization. The largest cities among them, identified as 'world cities' [2], are often the most densely connected to this international network; and primate cities — the largest cities in a given country-are typically more connected to the international network of cities (with small-city resort destinations being the exception), while smaller secondary cities and towns are often connected to this global network only through the larger cities in their respective countries.

There is no doubt, therefore, that larger metropolitan areas receive more international arrivals than smaller metropolitan areas or smaller cities and towns. This can be seen in Figure 5. The figure is focused on the 176 U.S. metropolitan areas that received international passengers between January and June of 2019, graphing the number of international arrivals on the Y-axis against the population of the metropolitan area on the x-axis [27]. Clearly, the larger the population of the metropolitan area, the larger the number of international arrivals: a city with double the population of a smaller one received more than 7 -fold the number of international passengers than the smaller city. 


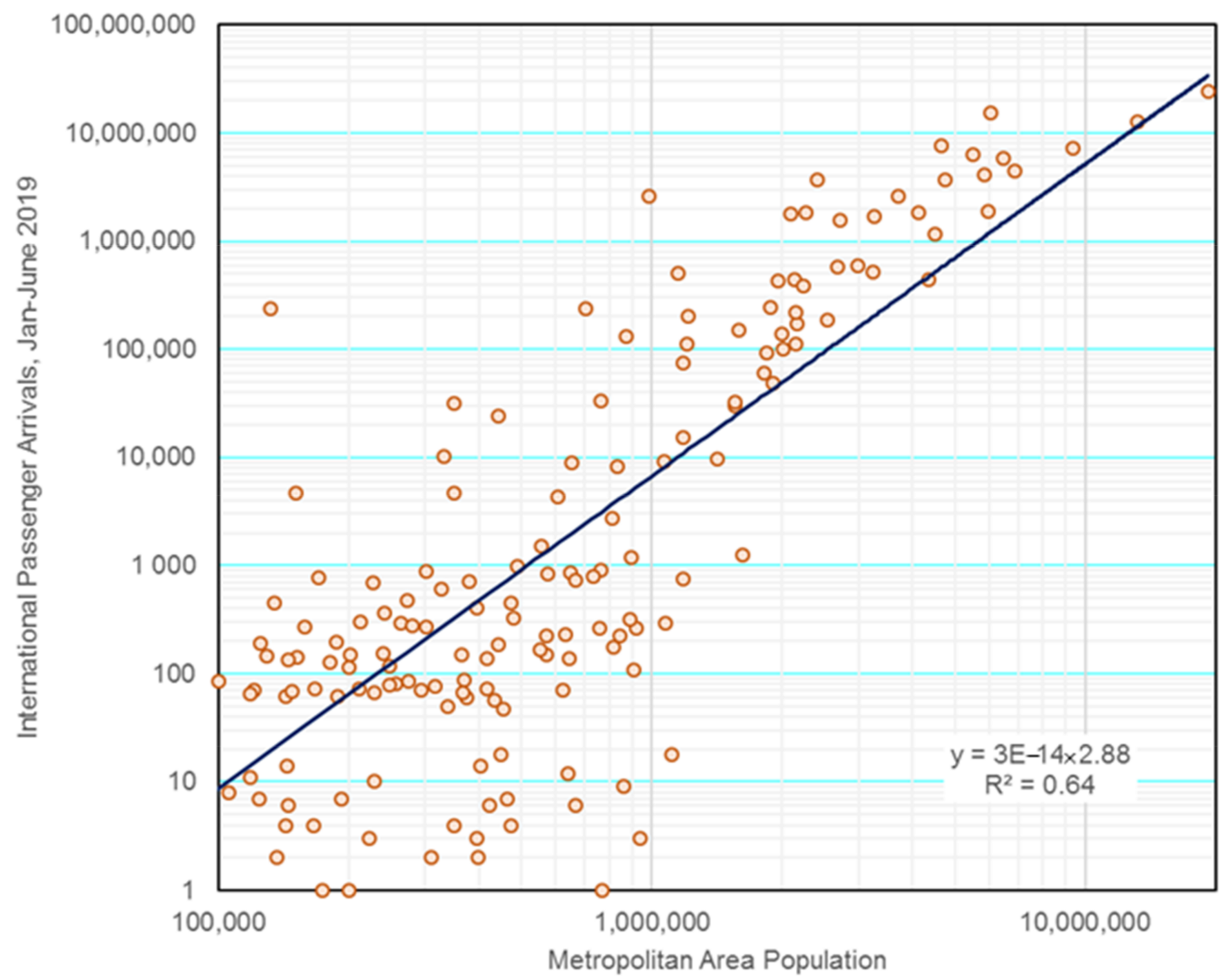

Figure 5. International arrivals during January-June 2019 as a function of their population in the 176 U.S. metropolitan areas that had international arrivals.

Since it is abundantly clear that the COVID-19 pandemic originated outside the United States, we can safely assume that it was brought to the United States by international travelers that arrived at international airports in larger metropolitan areas. We should not be surprised, therefore, if the onset of COVID-19 infections and deaths would occur earlier in large, multi-county metropolitan areas than in small-city counties, and earlier in small-city counties than in rural counties. This is the claim of the Onset Hypothesis.

The Onset Hypothesis focuses on the dates at which the first COVID-19 case and the first COVID-19 deaths were recorded in a given U.S. county. Table 2 below records the average dates for the onset of both cases and deaths for four categories of counties.

It tells us, with a high degree of statistical confidence, that the Onset Hypothesis cannot be rejected by the available data. The onset of COVID-19 cases in counties within multi-county MSAs (metropolitan statistical areas) occurred, on average, between the 20th and the 21st of March, 2020; in small cities, it occurred, on average, between the 25th and 27th of March, 2020, i.e., 6 days later; and in rural counties, it occurred, on average, between the 14th and 18th of April, 2020, i.e., 21 days later than in small cities and 27 days later than in multi-county MSAs. The table also tells us that the onset of COVID-19 deaths in counties within multi-county MSAs occurred, on average, between the 23rd and 29th of April, 2020; in small cities, it occurred, on average, between the 7th and 14th of May, 2020, i.e., 14 days later; and in rural counties, it occurred, on average, between the 15th and 22nd of June, 2020, i.e., 39 days later than in small cities and 53 days later than in multi-county 
MSAs. (While all tables report population-level statistics, we include confidence intervals around group averages to account for reporting and measurement error).

Table 2. The onset of COVID-19 cases and deaths in the three categories of U.S. counties, showing that the onset of the pandemic occurred significantly earlier in Multi-county MSAs.

\begin{tabular}{|c|c|c|c|c|}
\hline & All Counties & Multi-County MSAs & Small Cities & Rural Counties \\
\hline \multicolumn{5}{|l|}{ County Date at Onset of Cases } \\
\hline Average & 2-April & 20-March & 26-March & 16-April \\
\hline $95 \mathrm{CI}$ & 1-April-3-April & 20-March-21-March & 25-March-27-March & 14-April-18-April \\
\hline \multicolumn{5}{|l|}{ County Date at Onset of Deaths } \\
\hline Average & 18-May & 26-April & 10-May & 19-June \\
\hline $95 \mathrm{CI}$ & 16-May-20-May & 23-April-29-April & 7-May-14-May & 15-June-22-June \\
\hline
\end{tabular}

We can conclude this section by observing that the onset of the COVID-19 pandemicand probably the onset of future pandemics originating abroad-clearly occurred earlier in multi-county MSAs, larger metropolitan areas that are more interconnected-through dense airline networks-with the world outside the United States. In this important sense, these large urban areas are distinct from the rest of the country, suggesting that they may indeed require a specific metropolitan response to the pandemic, over and above the existing federal, state, and county response.

\section{The Peak Hypothesis}

The peak of COVID-19 cases and deaths occurred earlier in multi-county metropolitan areas than in small-city counties, and earlier in small-city counties than in rural areas.

Peak values and dates for cases and deaths were identified as the maximum values of seven- day averages of daily new cases and deaths, subject to two conditions: First, that counties with zero values had no peak; and second, that the peak value was maintained for two weeks by 27 September 2020. In other words, counties that had maximum values less than two weeks before 27 September 2020 or, for that matter, on 27 September 2020, were not considered to have attained their peak values.

There are two possible reasons for hypothesizing that the peaks of either cases or deaths would occur earlier in larger multi-county metropolitan areas. The first is rather obvious: if the pandemic follows a regular pattern, then an earlier onset in a given county would be followed by an earlier peak. Moreover, since we have shown that larger multicounty metropolitan areas had earlier onsets of both cases and deaths, they should be expected to have earlier peaks of cases and deaths as well. The second reason follows the 'urban health advantage' hypothesis [1], elaborated upon further in the following section: larger cities have more evolved and more specialized health care systems than small-city counties and rural counties $[10,11]$ and can, therefore, be expected to have more and better tools for confronting the pandemic and getting control of it sooner; thus, we can expect peak cases and deaths to occur earlier in these places.

Table 3 below records the average dates for the peaks of both new cases and new deaths for four categories of counties. The results for peak cases are mixed. The peak of COVID-19 cases in counties within multi-county MSAs (metropolitan statistical areas) occurred, on average, between the 9th and 15th of July, 2020; in small cities, it occurred, on average, between the 12th and 19th of July, 2020, i.e., not significantly later than in multi-county MSAs; and in rural counties, it occurred, on average, between the 20th and 26th of July, 2020, i.e., significantly later than in both small cities and multi-county MSAs. The results for peak deaths are more emphatic. The table tells us that the peak of COVID-19 deaths in counties within multi-county MSAs occurred, on average, between the 26th of June and 4th of July, 2020; in small cities, it occurred, on average, between the 6th and the 
14 th of July, 2020, i.e., 10 days later; and in rural counties, it occurred, on average, between the 18th and 25th of July, 2020, i.e., 12 days later than in small cities and 22 days later than in multi-county MSAs.

Table 3. Average peak dates for COVID-19 cases and deaths in the three categories of U.S. counties, showing that the peak of the pandemic occurred significantly earlier in multi-county MSAs.

\begin{tabular}{|c|c|c|c|c|}
\hline & All Counties & Multi-County MSAs & Small Cities & Rural Counties \\
\hline \multicolumn{5}{|l|}{ County Date at Peak of Cases } \\
\hline $\begin{array}{l}\text { Average } \\
95 \mathrm{CI}\end{array}$ & $\begin{array}{r}\text { 17-July } \\
\text { 15-July-19-July }\end{array}$ & $\begin{array}{r}\text { 12-July } \\
\text { 9-July-15-July }\end{array}$ & $\begin{array}{r}\text { 16-July } \\
\text { 12-July-19-July }\end{array}$ & $\begin{array}{r}\text { 23-July } \\
\text { 20-July-26-July }\end{array}$ \\
\hline \multicolumn{5}{|l|}{ County Date at Peak of Deaths } \\
\hline $\begin{array}{l}\text { Average } \\
95 \mathrm{CI}\end{array}$ & $\begin{array}{r}\text { 10-July } \\
\text { 8-July-12-July }\end{array}$ & $\begin{array}{l}\text { 30-June } \\
\text { 26-June-4-July }\end{array}$ & $\begin{array}{r}\text { 10-July } \\
\text { 6-July-14-July }\end{array}$ & $\begin{array}{r}\text { 22-July } \\
\text { 18-July-25-July }\end{array}$ \\
\hline
\end{tabular}

We can, thus, conclude that the Peak Hypothesis cannot be rejected when we compare peak cases in urban versus rural counties: peaks in urban counties-i.e., multi-county MSAs and small cities-occurred significantly earlier than in rural counties. The hypothesis cannot be rejected in the case of peak deaths for all three categories of U.S. counties. Peak COVID-19 deaths occurred earlier in larger U.S. cities and metropolitan areas than in small-city counties, and earlier in small-city counties than in rural counties.

\section{Explaining the Timing of Peak Deaths vs. Peak Cases}

The reader may notice that peak dates for cases in all four categories of counties occurred significantly later than the peak dates for deaths. This is counter-intuitive: If deaths occur some weeks after contracting the virus, then-other things being equal-peak deaths should occur after peak cases. This initially surprised us as well, but it does make sense. During the initial stage of the pandemic, there were fewer tests and many tests were restricted to those already exhibiting symptoms. There was also some confusion as to proper treatment, as well as fewer therapeutics and hence a higher Case Fatality Rate-the ratio of deaths to cases - than in later stages. COVID-19 deaths in the U.S. as a whole peaked earlier, while cases kept increasing, attaining a peak some three months later (see Figure 6). In later months, with increased testing of less vulnerable populations and improved treatment regimes, the number of cases kept increasing while the Case Fatality Rate declined (see Figure 7).

We can conclude this section by observing that the peak cases and deaths during the COVID-19 pandemic - and probably the peaks of future pandemics as well-occurred earlier in multi-county MSAs, and in the case of peak deaths significantly earlier. Again, we note that counties in multi-county metropolitan areas need to be viewed as a special class in itself, to be distinguished from other U.S. counties, a class that may be the object of more carefully targeted responses to the pandemic than those aimed at municipalities, counties, states, or the country as a whole. 


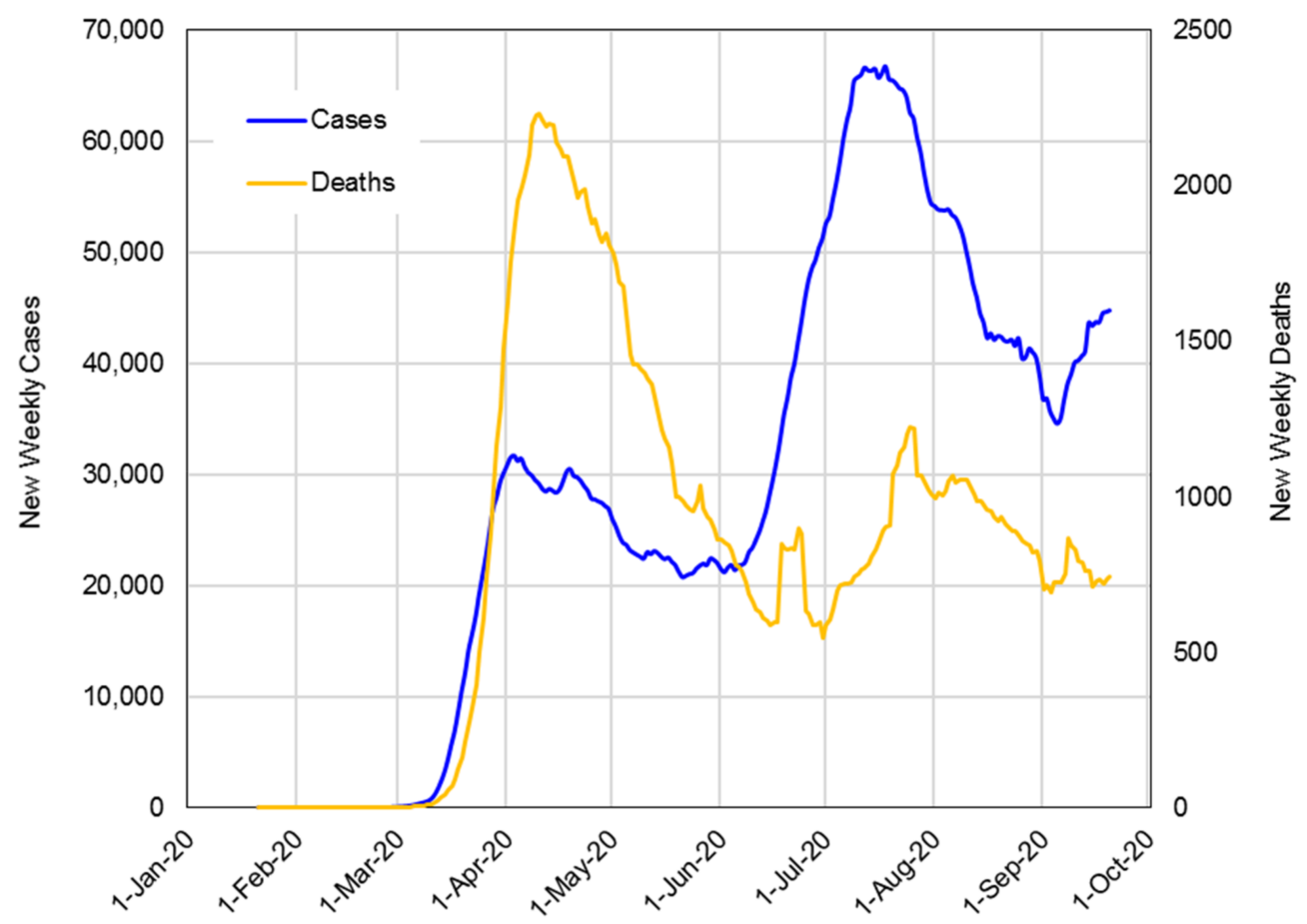

Figure 6. Weekly new cases and deaths in the U.S. to 27 September 2020, showing that peak deaths occurred earlier than peak cases during this period.

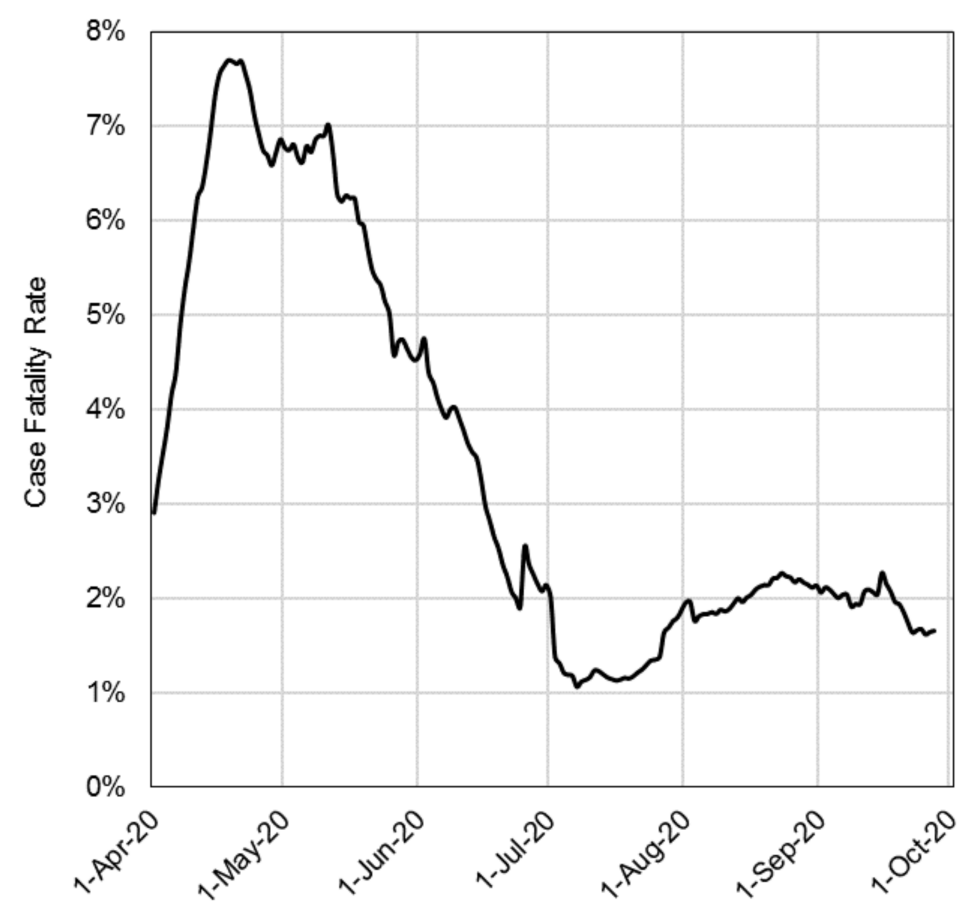

Figure 7. The decline in the Case Fatality Rate-the ratio of COVID-19 deaths to cases-in the U.S. during the 1 April to 27 September 2020 period.

\section{The Scaling Hypothesis}

Multi-county metropolitan areas had more than their shares of COVID-19 cases and deaths than their shares in the population.

Are contemporary cities - and large cities or global cities, in particular-more vulnerable to epidemics, because they thrive on their high density of human contacts, or are 
they better at confronting and managing them, because of their superior levels of financial, organizational, and creative resources? Some observers, like Richard Horton, the editor of Lancet (quoted [1]) believe that "... for all of its rational efficiency and benevolent intent, the city is likely to be the death of us." Others, like Reference [1], consider the matter an open question: "can global cities take effective measures to protect themselves against emerging threats to population health, or will these vulnerable giants increasingly be viewed as risky places to live?" Rodwin examines the evidence for "the sick city" and "the healthy city." He demonstrates that it is clearly mixed-contemporary large cities have better outcomes along some health measures and worse along others-and concludes that "[t]here is insufficient evidence, however, to provide strong support for either the urban health penalty or the urban health advantage hypotheses" [1] (p. 33). In this paper, we explore evidence from the current COVID-19 pandemic in the U.S. that lends partial, though not conclusive, support to the urban health penalty hypothesis, shedding some light on the question posed by Rodwin.

Geoffrey West [9] postulates that like economic activity or innovation, the spread of infectious disease - in our case, the spread of the COVID-19 pandemic - is superlinear with the population size of cities: a doubling of city size is postulated to be associated with a $15 \%$ per capita increase in cases or deaths from infectious disease. This postulate thus supports the urban health penalty hypothesis advanced by Rodwin. In an earlier paper [28], we explored the available COVID-19 data in a 20-week longitudinal study (6 March-23 July 2020) of the 384 U.S. metropolitan statistical areas (MSAs) and confirmed West's postulate:

During the last 10 weeks, the numbers have tended to converge: (1) a city with double the population of a smaller one can be expected to have $17 \%$ more cases per capita and $28 \%$ more deaths per capita than the smaller city ... . Larger cities have more than their share of cases and deaths in part because the larger the city, the larger the number of possible interactions among its inhabitants. And it is this larger number, rather than the overall average proximity of people to each other-expressed by the average density in the city—that accounts for that larger share [28] (p. 1).

Our earlier paper [28], thus, supported the Scaling Hypothesis for U.S. metropolitan areas: Metropolitan areas with larger populations had more than their shares of COVID-19 cases and deaths than their respective population shares would suggest. This finding lends indirect support to the Scaling Hypothesis presented here, suggesting that counties in large multi-county metropolitan statistical areas (MSAs) will have more than their share of cumulative COVID-19 cases and deaths as of 27 September 2020 than their relative population shares.

In this section, we explore the Scaling Hypothesis for all U.S. counties on three different dates: 27 March, 27 June, and 27 September 2020. For all three dates, we compare the average cumulative numbers of COVID-19 cases and deaths-as well as cases and deaths per 100,000 people-in 3142 single counties that form multi-county MSAs, small cities, and rural counties. The reason for choosing three dates is that we suspect that the Scaling Hypothesis may weaken over time, as large cities-which started out with an urban health penalty-gradually begin to accumulate an urban health advantage.

Because, as we have seen earlier (Table 1), counties in multi-county MSAs have, on average, considerably larger populations than those of small-city counties and rural counties, they also have significantly larger cumulative numbers of cases and deaths than counties in the two latter categories, as shown in Table 4 below. Indeed, it should come as no surprise that counties in multi-county MSAs have significantly more cases and deaths than small-city counties and rural counties, at least in part because they have larger populations. 
Table 4. Cumulative COVID-19 cases and deaths in four categories of U.S. counties on 27 March, 27 June, and 27 September 2020 .

All Counties Multi-County MSAs Small Cities Rural Counties

$\begin{array}{llrrrr}\text { Average } & & & & & \\ & \text { 27-March } & 32 & 88 & 10 & 1 \\ & \text { 27-June } & 824 & 599 & 464 & 65 \\ & \text { 27-September } & 2250 & 5226 & 1689 & 254 \\ \text { 95\% CI } & & & & \\ & & & & & \\ & \text { 27-March } & 21-42 & 57-119 & 3-12 & 57-73 \\ & \text { 27-June } & 683-966 & 1596-2403 & 377-551 & 237-272\end{array}$

Cumulative Deaths

\begin{tabular}{llrrrr} 
Average & & & & & \\
& 27-March & 2 & 3 & 24 & 2 \\
& 27-June & 65 & 127 & 42 & 6 \\
& 27-September & 65 & & & \\
$95 \%$ CI & & & & \\
& & & $-1-8$ & $0-1$ & $0-3$ \\
& 27-March & $0-3$ & $94-160$ & $17-31$ & $4-6$ \\
& 27-June & $50-80$ & $124-191$ & $33-50$ & $5-6$ \\
\hline 27-September & $53-76$ & &
\end{tabular}

The Scaling Hypothesis calls for comparing cumulative cases and deaths in these three categories of counties while accounting for the differences in their populations. Instead of comparing the cumulative number of cases and deaths in these three categories of U.S. counties, we compare cases and deaths per 100,000 people. The Scaling Hypothesis leads us to expect that these numbers would also be significantly higher for multi-county MSAs. Table 5 below records the average cumulative cases and deaths per 100,000 people for four categories of counties on 27 March, 27 June, and 27 September 2020. 
Table 5. Cumulative COVID-19 cases and deaths per 100,000 people in four categories of U.S. counties as of 22 April and 27 September 2020.

\begin{tabular}{|c|c|c|c|c|c|}
\hline & & All Counties & Multi-County MSAs & Small Cities & Rural Counties \\
\hline \multicolumn{6}{|l|}{ Cumulative Cases } \\
\hline Average & & & & & \\
\hline & 27-March & 10 & 16 & 9 & 5 \\
\hline & 27-June & 489 & 601 & 524 & 379 \\
\hline & 27-September & 1892 & 2011 & 1992 & 1736 \\
\hline $95 \%$ CI & & & & & \\
\hline & 27-March & $9-11$ & 14-19 & $7-11$ & $4-6$ \\
\hline & 27-June & $462-515$ & $551-651$ & $470-577$ & $343-416$ \\
\hline & 27-September & 1842-1942 & 1929-2094 & 1894-2091 & 1655-1817 \\
\hline \multicolumn{6}{|l|}{ Cumulative Deaths } \\
\hline \multicolumn{6}{|l|}{ Average } \\
\hline & 27-March & 0.2 & 0.4 & 0.1 & 0.1 \\
\hline & 27-June & 17 & 25 & 16 & 11 \\
\hline & 27-September & 42 & 48 & 43 & 37 \\
\hline \multicolumn{6}{|l|}{$95 \%$ CI } \\
\hline & 27-March & $0.2-0.3$ & $0.3-0.6$ & $0.1-0.2$ & $0-0.2$ \\
\hline & 27-June & $16-18$ & $22-27$ & $14-18$ & 10-13 \\
\hline & 27-September & $40-44$ & $45-51$ & $40-47$ & $34-40$ \\
\hline
\end{tabular}

The results for cumulative cases per 100,000 are more nuanced. The average value in individual counties within multi-county MSAs was significantly higher than the average value for small cities on 27 March 2020, but by 27 June 2020, it was no longer significantly higher. The average number of COVID-19 deaths per 100,000 people in multi-county MSAs was still significantly higher than that of small-city counties on 27 June 2020, but by 27 September 2020, it was no longer significantly higher. Both cases and deaths per 100,000 people were significantly higher in multi-county MSAs and in small-city counties than in rural counties on all three dates.

Again, we can conclude this section by observing that the cumulative cases and deaths during the COVID-19 pandemic were significantly higher in multi-county MSAs than in small-city and rural counties early in the pandemic. The average number of cases and deaths per 100,000 people was no longer significantly higher than the average number in small-city counties by 27 September 2020. More generally, the differences in the average numbers of cases and deaths per 100,000 people between all categories of counties have tended to become smaller over time. Still, we note that these results lend support to our contention that-especially in the early months of the pandemic-counties in multi-county metropolitan areas needed to be viewed as a special class in itself, to be distinguished from other U.S. counties, a class that may require a calibrated response to the COVID-19 pandemic as well as to future pandemics.

\section{The Neighbor Hypothesis}

Levels of COVID-19 cases and deaths in counties within multi-county metropolitan areas were more strongly related to respective levels in their neighboring counties than small-city counties or rural counties.

This hypothesis is the central hypothesis of this paper. It originates with Tobler's First Law of Geography- "Everything is related to everything else, but near things are more related than distant things" [13]—and amplified by Bertaud's observation that multicounty metropolitan areas form single, integrated, and densely-connected metropolitan labor markets [12]. Our research [29] demonstrates that U.S. metropolitan areas form single 
labor markets, as Figure 8 shows. In this figure, we showed maps of a random sample of 200 commuting trips in the two metropolitan areas of Chicago and Atlanta. It shows clearly that their residents live everywhere and work everywhere. The Neighbor Hypothesis postulates that-because multi-county MSAs are, on average, closer to each other (see Table 1) and because they form single, integrated economies, we can expect the intensity of linkages among them to result in strong neighbor effects linked to pandemics in general and to the COVID-19 pandemic in particular.

We explore these neighbor effects by comparing several metrics between counties and their immediate neighbors. More specifically, we compare the metric for a given U.S. county with the average for this metric in the immediate counties surrounding it, as explained in the methodology section. The four metrics of interest here are essentially the same as those introduced in the previous three sections with the addition of one metric: (1) dates of onset of cases and deaths; (2) dates of peak cases and deaths; (3) peak cases and deaths per 100,000 people; and (4) cumulative cases and deaths per 100,000 people on 27 September 2020. We hypothesize that neighborhood relationships will be stronger (i.e., neighboring county values will be closer to county values) for multi-county MSAs.

We test the similarity of values for each metric between counties and their neighbors in three complementary ways. First, to compare dates, we simply take the absolute value of the difference between a county date and the average date for its neighbors, measured in days. Second, to compare metric values that are not dates, we construct a 'similarity index' for each metric, an index that is equal to the absolute value of the difference between the two metrics divided by their average values. For example, if a county had 20 cumulative deaths per 100,000 people on 27 September 2020 and its neighbors had an average of 12 , then the similarity index for this county will be: $|20-12| /((20+12) / 2)=0.5=$ $50 \%$. Having constructed a similarity index for each country for each metric -an index that can vary between 0 and 200\%-we then compare similarity indices for each of the four categories of counties. Third, we look at the correlation between county values and neighboring county values - be they dates, peak values, or cumulative values-for the three categories of counties, to see whether the correlations for counties in multi-county MSAs are higher than those for counties with small cities and for rural counties. More specifically, in the following four sections, we compare: (1) the dates of onset of cases and deaths; (2) the peak dates of cases and deaths; (3) cases and deaths per 100,000 at peak; and (4) cumulative cases and deaths per 100,000 on 27 September 2020.
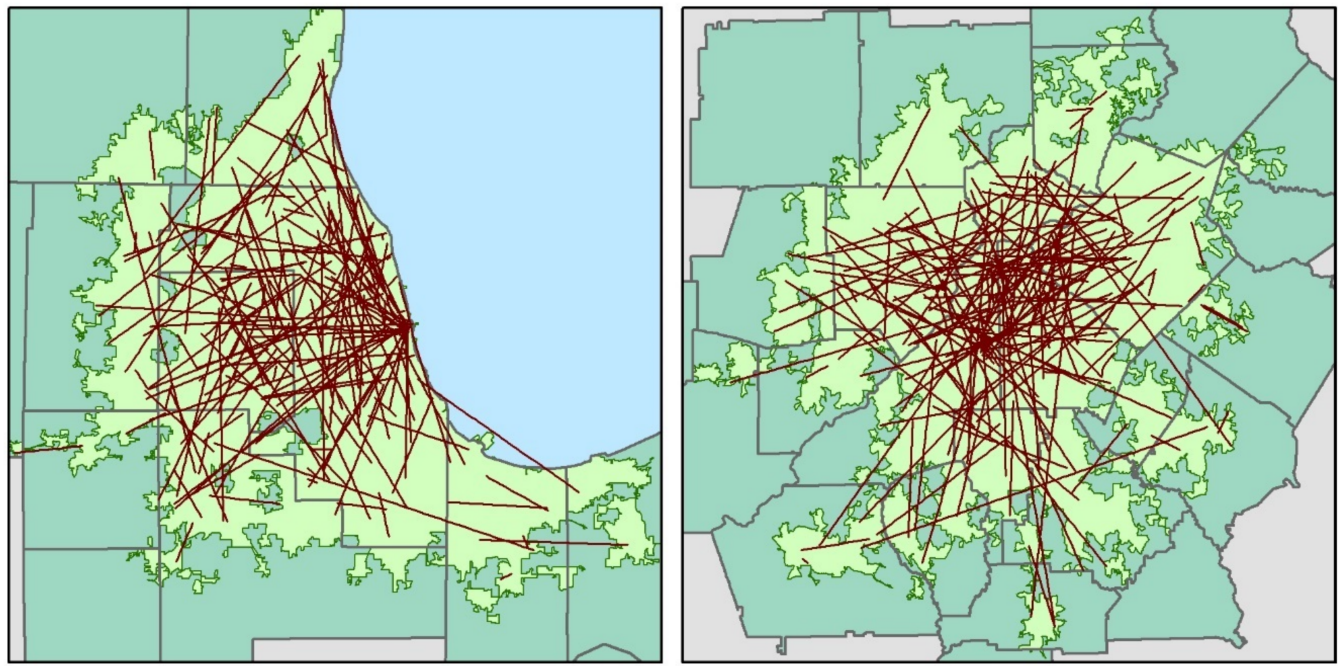

Figure 8. A random sample of 200 commuting trips in the urbanized areas of metropolitan Chicago (left) and metropolitan Atlanta (right), showing that people in these integrated labor markets live everywhere and work everywhere. Block-level flows were extracted from the Longitudinal EmployerHousehold Dynamics origin-destination dataset for 2017 [30]. 


\subsection{Comparing Dates of Onset of Cases and Deaths}

The Onset Hypothesis discussed earlier focused on demonstrating that the onset of COVID-19 cases and deaths occurred earlier in multi-county MSAs than in small cities, and earlier in small cities than in rural counties. The Neighbor Hypothesis looks at the onset of cases and deaths in a different way. It postulates that-because counties in multi-county MSAs are more densely connected to their neighbors-the onset dates of cases and deaths in counties in multi-county MSAs will be closer to the onset dates of their immediate neighbors than in counties with small cities or rural counties.

Table 6 below displays the absolute differences in the dates of onset of both cases and deaths for the four categories of counties. These absolute differences in onset dates are significantly smaller in multi-county MSAs than in small-city counties and rural counties. The onset of COVID-19 cases in counties within multi-county MSAs occurred within 10-11.2 days of the onset of cases in their neighboring counties; in small cities, it occurred within 11.4-14 days, and in rural counties, it occurred within 24-27 days. In the case of deaths, the differences are all statistically significant as well: the onset of COVID-19 deaths in counties within multi-county MSAs occurred within 25-30 days of the onset of deaths in their neighboring counties; in small cities, it occurred within 34-39 days, and in rural counties, it occurred within 55-61 days.

We now look at the correlations between onset dates for counties and their neighbors. We postulate that these correlations will be higher for multi-county MSAs. The table shows that the correlation between the onset dates for both COVID-19 cases and deaths ( 0.37 and 0.31 , respectively) are considerably higher for counties in multi-county MSAs than those in small cities or rural counties.

We can conclude that the results of the two statistical tests comparing the onset of cases and deaths in counties and their immediate neighbors support the Neighbor Hypothesis or, more precisely, provides us with a high degree of statistical confidence for not rejecting it.

Table 6. The absolute differences in dates of the onset of COVID-19 cases and deaths between counties and their immediate neighbors in four categories of U.S. counties.

\begin{tabular}{|c|c|c|c|c|}
\hline & All Counties & Multi-County MSAs & Small Cities & Rural Counties \\
\hline \multicolumn{5}{|c|}{ Absolute Difference in Onset of Cases (days) } \\
\hline Average & 17 & 11 & 13 & 25 \\
\hline $95 \%$ CI & $16-18$ & $10-11$ & $11-14$ & $24-27$ \\
\hline Correlation Coefficient & 0.38 & 0.37 & 0.24 & 0.30 \\
\hline \multicolumn{5}{|c|}{ Absolute Difference in Onset of Deaths (days) } \\
\hline Average & 40 & 28 & 37 & 58 \\
\hline $95 \% \mathrm{CI}$ & $38-42$ & $25-30$ & $34-39$ & $55-61$ \\
\hline Correlation Coefficient & 0.34 & 0.31 & 0.28 & 0.27 \\
\hline
\end{tabular}

\subsection{Comparing Peak Dates of Cases and Deaths}

Peak values and dates for cases and deaths were identified as the maximum values of these seven-day averages, subject to two conditions: First, that counties with zero values had no peak; and second, that the peak value was maintained for two weeks by 27 September 2020. In other words, counties that had maximum values less than two weeks before 27 September 2020 or, for that matter, on 27 September 2020, were not considered to have attained their peak values.

The Neighbor Hypothesis leads us to believe that, as with the onset dates of COVID19 cases and deaths, the peak dates in counties in Multi-county MSAs will be closer to the average peak dates of their neighboring counties than in small-city counties or rural counties. We can explore whether this is true by looking at the absolute difference in peak dates between counties and their neighbors in the four categories of counties, as well as at 
the correlations between peak dates in counties and their immediate neighbors in these four categories of counties.

Table 7 below shows that, on average, the absolute values of the differences in peak dates of COVID-19 cases between counties and their immediate neighbors in multi-county MSAs varied between 22 and 26 days; in small-city counties, it varied between 27 and 31 days; and in rural counties, it varied between 28 and 32 days. The difference between the last two categories of counties is not statistically significant, but the difference between multi-county MSAs and both small-city counties and rural counties is. In the case of deaths, the same pattern can be observed: the peak of COVID-19 deaths in counties within multicounty MSAs occurred within 30-34 days of the date of peak deaths in their neighboring counties; in small-city counties, it occurred within 35-40 days, and in rural counties, it occurred within 36-41 days. We can conclude that comparing the absolute differences in peak dates between counties and their neighbors in these three categories of U.S. counties does lends strong support to the Neighbor Hypothesis.

We can also ask whether the correlations between peak dates in counties and their neighbors are higher in multi-county MSAs than in small cities or in rural counties. We postulate that they are. Table 7 shows that the correlation between the peak dates for both COVID-19 cases and deaths (0.62 and 0.57 , respectively) are considerably higher for counties in multi-county MSAs than those in small cities or rural counties.

To conclude, there are statistically significant differences between counties in multicounty MSAs on the one hand and small-city and rural counties on the other in the absolute differences between their peak dates and their immediate neighbors' peak dates for both COVID-19 cases and dates. Moreover, the correlation between peak dates in counties in multi-county MSAs and their neighbors is considerably higher than in small cities and rural counties. Comparing peak dates, therefore, also lends considerable support to the Neighbor Hypothesis.

Table 7. The absolute differences in peak dates of COVID-19 cases and deaths between counties and their immediate neighbors in four categories of U.S. counties.

All Counties Multi-County MSAs Small Cities Rural Counties

Absolute Difference in Peak Cases Dates (days)

$\begin{array}{lrrr}\text { Average } & 27 & 24 & 30 \\ 95 \% \text { CI } & 26-29 & 22-26 & 29-31 \\ \text { Correlation Coefficient } & 0.50 & 0.62 & 0.48 \\ & & & \\ \text { Absolute Difference in Peak Deaths Dates (days) } & & 32 & 32 \\ \text { Average } & 36 & 30-34 & 35-40 \\ 95 \% \text { CI } & 34-37 & 0.57 & 0.39 \\ \text { Correlation Coefficient } & 0.45 & & 36-41 \\ \end{array}$

\subsection{Comparing Cases and Deaths per 100,000 at Peak}

The Neighbor Hypothesis implies that, as with the onset and peak dates of COVID-19 cases and deaths, the similarity among neighboring counties in the numbers of COVID-19 cases and deaths per 100,000 people at peak will be greater in multi-county MSAs than in small-city counties or rural counties. We can explore whether this is true by looking at the normalized. As explained in the methodology section, the absolute value of the difference between two values is normalized by dividing it by the average of those two values. Absolute difference in peak values between counties and their neighbors in the four categories of counties, as well as at the correlations between peak values in counties and their immediate neighbors in these four categories of counties. Table 8 below display the results of these comparisons for the four categories of U.S. counties. It shows that the normalized absolute differences in peak cases per 100,000 people between counties 
and their neighbors in multi-county MSAs (39 $\pm 2 \%)$ is significantly lower than those of small cities ( $49 \pm 3 \%$ ) and rural counties ( $54 \pm 2 \%$ ), but that those of small cities are not significantly lower than those of rural counties. The normalized absolute differences in peak deaths per 100,000 people between counties and their neighbors in multi-county MSAs $(50 \pm 3 \%)$ is not significantly lower than that of small cities $(55 \pm 3 \%)$ but is significantly lower than that of rural counties $(59 \pm 3 \%)$, yet the average value for small cities is not significantly lower than that of rural counties.

Table 8. The normalized absolute differences in peak COVID-19 cases and deaths per 100,000 between counties and their immediate neighbors in four categories of U.S. counties.

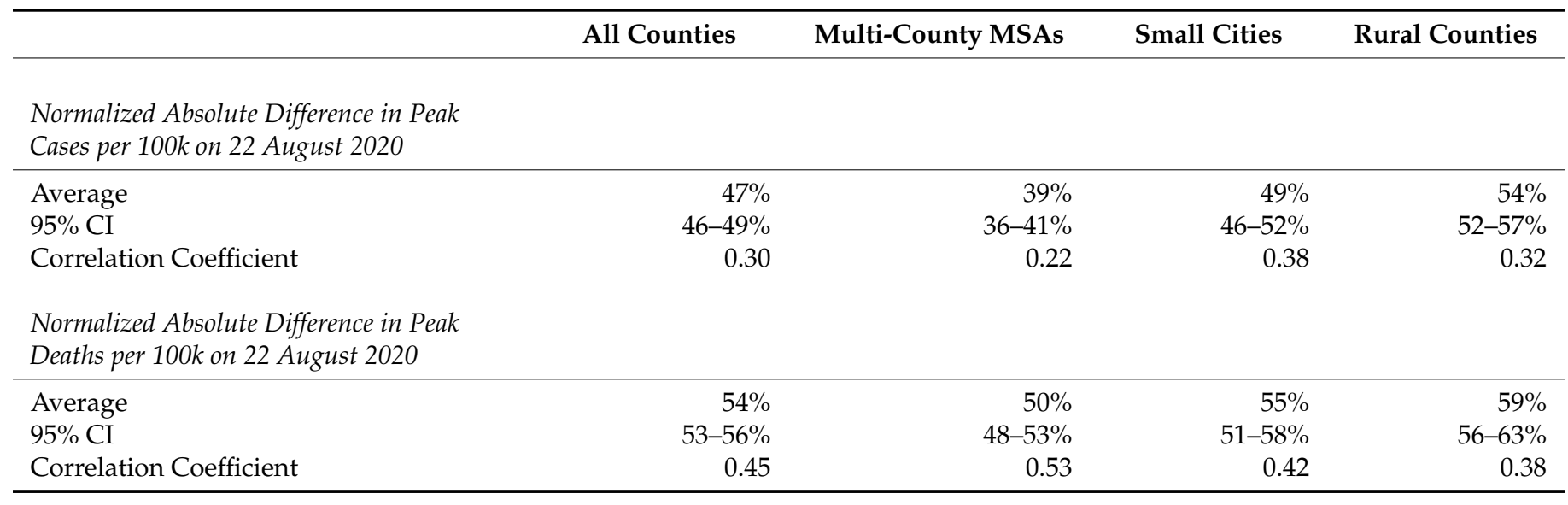

As with the onset and peak dates, we can ask whether the correlations between peak cases and deaths per 10,000 people in counties and their neighbors are higher in multicounty MSAs than in small cities or in rural counties. Again, we postulate that they are. Table 8 shows that the correlation coefficient between the peak cases per 100,000 in counties in multi-county MSAS and their immediate neighbors is, in fact, lower than the correlation between peak cases per 100,000 small-city counties and rural counties ( 0.22 vs. 0.38 and 0.32). However, for peak deaths per 100,000 , the correlation coefficient is considerably higher for counties in multi-county MSAs than those in small cities or rural counties $(0.53$ vs. 0.42 and 0.38 ).

To conclude, comparing the differences in the numbers of cases and deaths at peak between counties and their immediate neighbors provides additional, though weak, statistical support for the Neighbor Hypothesis. We find that the absolute differences in cases per 100,000 in counties in multi-county MSAs are significantly smaller than those in small-city counties and rural counties. This finding is important, but we should keep in mind that it is moderated by the finding that the correlation coefficients between the values for counties and their neighbors are lower than those in small-city and rural counties.

\subsection{Comparing Cumulative Cases and Deaths per 100,000 on 27 September 2020}

Finally, we examine the relationships between the cumulative numbers of COVID-19 cases and deaths in counties and their neighbors. Again, the Neighbor Hypothesis postulates that the numbers of cases and deaths in counties in multi-county MSAs will be similar to those of their neighbors and that the level of similarity will be higher than in small-city counties or rural counties and their neighbors. Table 9 below display the results of these comparisons for the four categories of U.S. counties on 27 September 2020. It shows that the normalized absolute differences in cumulative values of cases and deaths in multi-county MSAs (33 $\pm 2 \%$ for cases and $59 \pm 3 \%$ for deaths) are significantly lower than those of small cities (37 $\pm 2 \%$ for cases and $70 \pm 4 \%$ for deaths) and that those of small cities are significantly lower than those of rural counties ( $49 \pm 2 \%$ for cases and $104 \pm 4 \%$ for deaths).

The correlation coefficient between the cumulative cases per 100,000 on 27 September 2020 in counties in multi-county MSAs and their immediate neighbors is, in fact, smaller 
than the coefficients for small-city counties and rural counties (0.61 vs. 0.67 and 0.62 ). However, for cumulative deaths per 100,000 , the correlation coefficient is considerably higher for counties in multi-county MSAs than those in small cities or rural counties $(0.74$ vs. 0.67 and 0.57$)$.

Table 9. The normalized absolute differences in cumulative COVID-19 cases and deaths per 100,000 between counties and their immediate neighbors in four categories of U.S. counties on 27 September 2020.

All Counties Multi-County MSAs Small Cities Rural Counties

Normalized Absolute Difference in Peak

Cases per 100k on 22 August 2020

\begin{tabular}{lrrrr} 
Average & $41 \%$ & $33 \%$ & $37 \%$ & $49 \%$ \\
$95 \%$ CI & $40 \%-42 \%$ & $32 \%-35 \%$ & $35 \%-39 \%$ & $47 \%-52 \%$ \\
Correlation Coefficient & 0.63 & 0.61 & 0.67 & \\
& & & & \\
Normalized Absolute Difference in Peak & & & & \\
Deaths per 100k on 22 August 2020 & & $59 \%$ & $70 \%$ & $104 \%$ \\
Average & $80 \%$ & $56 \%-62 \%$ & $66 \%-74 \%$ & $100 \%-108 \%$ \\
$95 \%$ CI & $78 \%-83 \%$ & 0.74 & 0.67 & 0.57 \\
Correlation Coefficient & 0.65 & & & \\
\hline
\end{tabular}

Again, we can conclude that comparing the differences in the cumulative numbers of cases and deaths 8 months after the onset of the COVID-19 epidemic between counties and their immediate neighbors provides additional statistical support for the Neighbor Hypothesis. We find that the absolute differences in both cases and deaths in counties in multi-county MSAs are significantly smaller than those in small-city counties and rural counties. This finding is important, but we should keep in mind that it is moderated by the finding that the correlation coefficients between the case values for counties and their neighbors are somewhat lower in large county MSAs than in small-city and rural counties.

In summary, comparing relationships between U.S. counties and their immediate neighbors as to the effects of the COVID-19 pandemic along numerous metrics leads us to conclude that the Neighbor Hypothesis is supported by the available statistical evidence on cases and deaths during the eight months for which data is now available: Levels of COVID-19 infections and deaths in U.S. counties are indeed related to respective levels in neighboring counties, and both dates and levels of cases and deaths in counties within multi-county metropolitan areas are more strongly related to respective dates and levels in their neighboring counties than small-city counties or rural counties.

\section{Conclusions}

We believe that the available data on COVID-19 cases and deaths in U.S. counties, now accumulated daily for more than eight months, shed light on an important, though largely ignored, question: What is the appropriate governmental jurisdiction for managing pandemics in general and the COVID-19 pandemic in particular? Confronting a real, rather than a theoretical pandemic, the answer to this question must be a pragmatic rather than an idealistic one, grounded in the prevailing historical context. Owing to our area of expertise and issues of data completeness and availability, we used empirical data from the U.S. to formulate a response to this question. In a recent review article of more than 63 COVID-19 spatial analyses in over 20 countries, we could not identify a similar study that investigated patterns of metropolitan contagion using a large cross-sectional, time-series group of submetropolitan zones for the duration of the pandemic, as we do [31]. Where and when the data allow, we hope that our analysis may be replicated, or similar analyses undertaken, so that we may deepen our understanding of how the pandemic spread across metropolitan areas in different economic, cultural, and policy contexts outside the U.S. In turn, we hope 
that this knowledge may help design policies and responses that are proportionate to the spatial dimensions of pandemics like COVID-19.

What is quite clear from our examination of the available data on the current pandemic in the U.S. is that individual counties-and especially counties within multi-county metropolitan areas-are not appropriate jurisdictions for managing the COVID-19 pandemic or any other pandemic. They are too interconnected with their neighboring counties. Hence, lax regulation or enforcement-of, say, 'social distancing' or 'shelter-in-place' regulations-in one county affects the spread of the pandemic among its neighboring counties and vice versa. Similarly, the decision to open schools, restaurants and bars, shops, factories, and offices early in one county may compromise decisions to open these establishments in neighboring counties in a more controlled fashion. Unsurprisingly, this simple insight is not universally shared. Several counties in California, for example, have repeatedly defied state COVID-19 related orders (see, e.g., [32,33]) insisting on retaining their power to decide when to open businesses and schools. Whether this makes sense or not depends, at least in part, on the inter-connectedness of these counties with their neighboring counties, and the way cases and deaths in one county impact the other, an issue that could indeed be decided with the help of the kind of evidence presented here.

In contrast to those California counties insisting on acting on their own, the South Coast Air Quality Management District-incorporating Los Angeles County and its three neighboring counties-functions effectively as a multi-county metropolitan jurisdiction on the key public health question of air quality, monitoring and regulating air quality in these four counties, which contain as many as 162 incorporated municipalities [24] and more than 17 million people. There is, therefore, a grounded hope that this kind of organization can be replicated to better confront future pandemics, and that better planning and preparation for future pandemics can include the creation of several multicounty metropolitan organizations, especially large ones than span several states, where, again, inconsistent and improperly coordinated state policies can compromise an effective metropolitan response.

This is not to suggest that multi-county, metropolitan pandemic-response districts will be charged with the entire range of responsibilities for managing pandemics. Far from it, they cannot be responsible for restricting international travel; for the development of new tests, new medical equipment, or new vaccines; for maintaining national stockpiles; or for issuing national or statewide guidelines. However, they can be responsible for coordinating metropolitan-wide pandemic databases; for coordinating metropolitan-wide testing and contact tracing; for coordinating the metropolitan-wide allocation of protective equipment, tests, and vaccines; for coordinating metropolitan-wide hospitalizations and the use of scarce hospital resources; and, most important, for coordinating metropolitanwide 'social distancing' and 'stay-at-home' measures as well as the gradual opening of schools, restaurants and bars, stores, factories, and offices. Responsibility for these policy measures, at the national or state level or at the county level-to the extent that is it based on remaining below measurable thresholds in cases, hospitalizations, or deaths as a precondition for reopening-makes little sense. These thresholds have to be set at the metropolitan scale, and only at the metropolitan scale, for them to provide the correct impetus for policy changes.

In addition to the various public health responsibilities that could, and probably should, be handled at the metropolitan scale, it is important to note that large metropolitan areas reveal major disparities in health outcomes, major inequities in access to healthcare, and barriers to such access by ethnic minorities (see, e.g., [34] (p. 449)). We note that these disparities and inequities-which are often spatial in nature, pertaining to low-income communities and neighborhoods-are also metropolitan in scale and cannot be properly addressed either at the municipal or at the county level and probably not at the state or federal level either. This is clearly illustrated in Figure 9, which shows the distribution of the lowest-income quartile and highest-income quartile areas in the Chicago and Atlanta urbanized areas. It is quite obvious that these discrepancies are not at the intra-county 
level but at the metropolitan level. Both rich and poor work in a single metropolitan labor market, but live in largely segregated residential areas, commuting to work from afar while sending their children to school and obtaining healthcare services nearby.
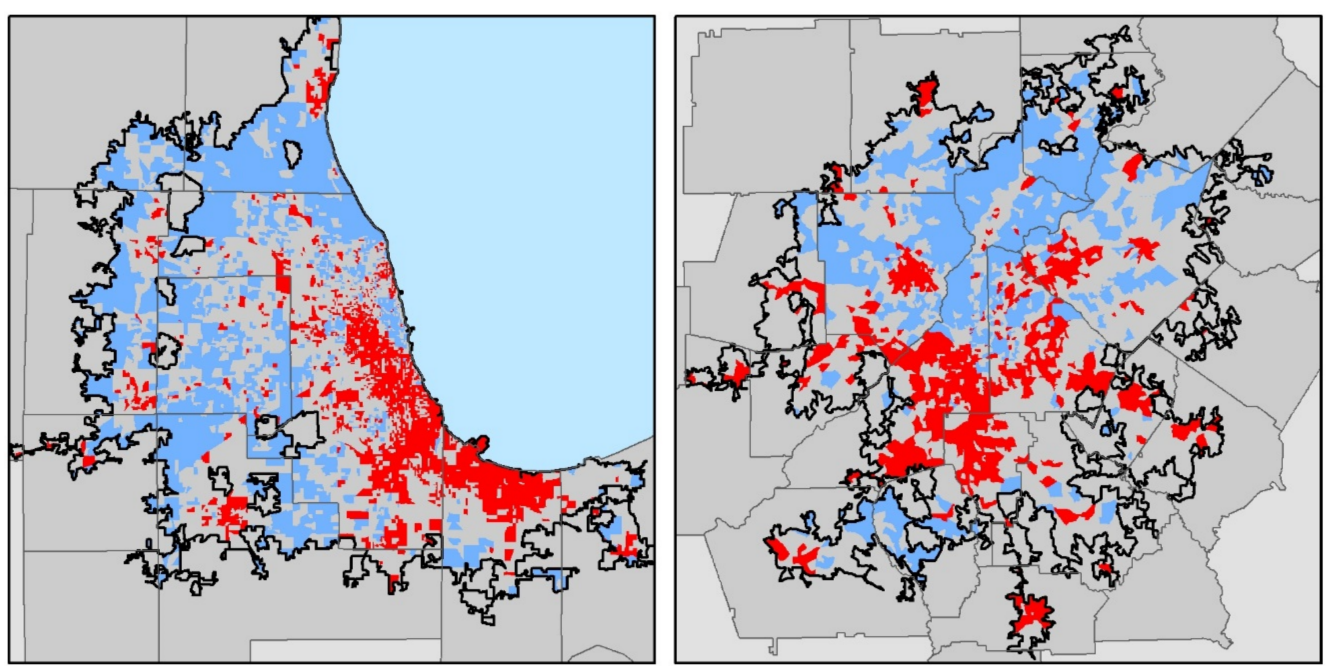

Figure 9. The spatial distribution of household incomes in the Chicago (left) and Atlanta (right) urbanized areas. The high-income quartile is shown in light blue and the low-income quartile is shown in red. American Community Survey 2014-2018 5-year estimates for census block groups.

The limited data on the geographic distribution of COVID-19 cases per 100,000 people by zip code (Figure 10), available for New York City-the only multi-county urban jurisdiction in the U.S. - clearly demonstrates that the COVID-19 pandemic hit low-income areas much harder than it hit high-income ones. Again, although New York City has only five counties, we see a clear distinction between them. The lower half of Manhattan (New York County) has high incomes and low numbers of cases per 100,000 people, while Bronx county to its north has low incomes and high numbers of cases per 100,000.
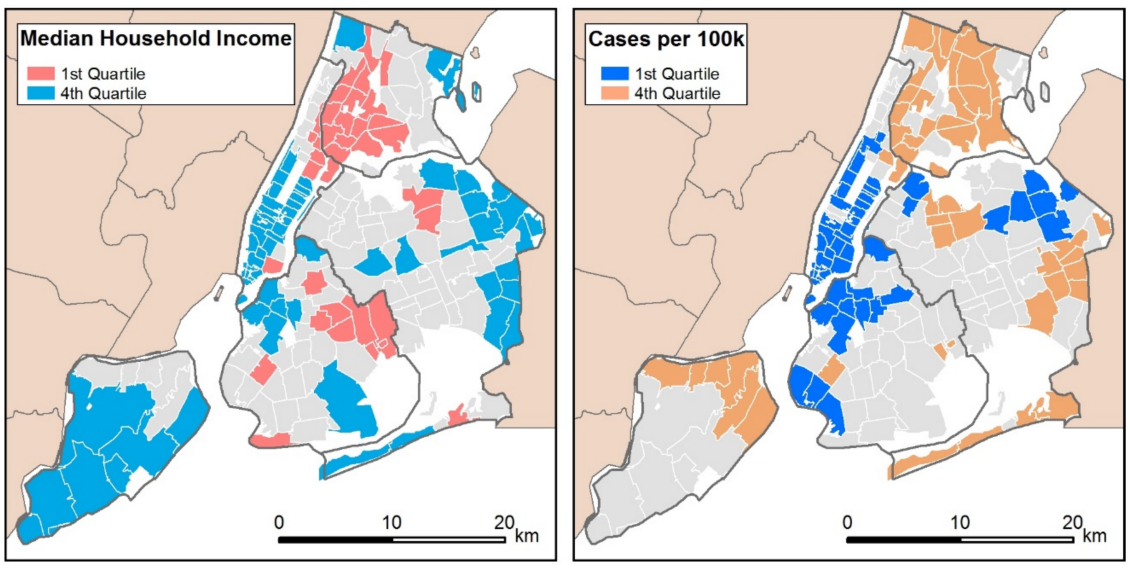

Figure 10. The spatial distribution of household incomes in New York City using 2014-2018 American Community Survey estimates (left), with the high-income quartile shown in light blue and the low-income quartile shown in light red; and the distribution of COVID-19 cases per 100,000 on 27 September (right), with the high-number quartile shown in orange and the low-number quartile shown in blue.

There is, thus, a good reason to believe that just as income inequalities, housing inequities, or educational imbalances cannot be adequately addressed at the small municipality or small county scale, neither can public health inequities. We believe that a metropolitan perspective could be best at identifying vulnerable communities and neigh- 
borhoods and addressing their public health needs in an equitable fashion, an insight made clear by [14] more than fifty years ago. This would be especially critical during the early stages of a pandemic that requires the judicious use of limited public health resources, be they hospital beds and staffs, intelligence gathering and processing capabilities, or medical equipment.

Surprisingly, none of these great metropolitan agglomerations-the largest artifacts ever assembled by mankind-are self-governing. They are kept from acquiring the means to govern themselves effectively by national governments and state governments that stand above them, or by county governments and municipal governments that stand below them.

We do realize that calling for the empowerment of metropolitan governmental structures that better conform to the geographic spread and response to pandemics in the midst of the highly politicized COVID-19 pandemic is a laughable proposition. Yet, we cannot but point out that given the evidence introduced in this paper, it is a serious proposition nonetheless, albeit one that may have to wait until cooler heads prevail. When it comes time for damage assessment, when it comes time to start preparing for the next pandemic, that proposition should be given the serious consideration it deserves.

Author Contributions: Conceptualization, Methodology, Analysis and Writing S.A. and A.B. All authors have read and agreed to the published version of the manuscript.

Funding: This research received no external funding.

Conflicts of Interest: The authors declare no conflict of interest.

\section{References}

1. Rodwin, V.G. Health and Disease in Global Cities: A Neglected Dimension of National Health Policy. In Networked Disease: Emerging Infections in the Global City; Ali, S.H., Keil, R., Eds.; Wiley-Blackwell Publishing: Oxford, UK, 2008 ; pp. $27-48$.

2. Hall, P. The World Cities; Weidenfeld \& Nicolson: London, UK, 1966.

3. Sassen, S. The Global City: New York, London, Tokyo, 2nd ed.; Princeton University Press: Princeton, NJ, USA, 2001.

4. $\quad$ Brenner, N.; Keil, R. The Global Cities Reader; Routledge: London, UK, 2006.

5. Beaverstock, V.J.; Faulconbridge, J.R.; Hoyler, M. Globalization and the City. In The Sage Handbook of Economic Geography; Leyshon, A., Lee, R., McDowell, L., Sunley, P., Eds.; Sage Publications: London, UK, 2009; pp. 189-201.

6. Curtis, S. Global Cities and the Transformation of the International System. Rev. Int. Stud. 2010, 37, 1-25. [CrossRef]

7. Christaller, W. Central Places in Southern Germany; Baskin, C.W., Ed.; Prentice-Hall: Englewood Cliffs, NJ, USA, 1966.

8. Daniels, P.W. Central Place Theory. International Encyclopedia of Geography: People, the Earth, Environment and Technology; Castree, N., Goodchild, M.F., Kobayashi, A., Marston, A.R., Liu, W., Richardson, D., Eds.; John Wiley \& Sons: New York, NY, USA, 2017. [CrossRef]

9. West, G. Scale: The Universal Laws of Life, Growth and Deaths in Organisms, Cities and Companies; Penguin: New York, NY, USA, 2017.

10. Smith, M.W. A Guide to the Delineation of Medical Care Regions, Medical Trade Areas and Hospital Service Areas. Public Health Rep. 1979, 94, 248-254. [PubMed]

11. Smith, M.W. Physician's Specialties and Medical Trade Areas: An Application of Central Place Theory. Papers and Proceedings of Applied Geography Conferences, West Point, NY, USA, January 1986. Available online: https://www.researchgate.net/ publication/271966248_Physician \T1 \textquoterights_Specialties_and_Medical_Trade_Areas_An_Application_of_Central_ Place_Theory (accessed on 22 December 2020).

12. Bertaud, A. Order Without Design: How Markets Shape Cities; MIT Press: Cambridge, MA, USA, 2018.

13. Tobler, W.R. A computer movie simulating urban growth in the Detroit region. Econ. Geogr. 1970, 46, 234-240. [CrossRef]

14. Burlage, R. New York City's Municipal Hospitals: A Policy Review; Institute for Policy Studies: Washington, DC, USA, 1967.

15. Chowkwanyun, M. The New Left and Public Health: The Health Policy Advisory Center, Community Organizing, and the Big Business of Health, 1967-1975. Am. J. Public Health 2011, 101, 238-249. [CrossRef] [PubMed]

16. OECD/European Commission. Cities in the World: A New Perspective on Urbanization; OECD Publishing: Paris, France, 2020.

17. Office of Management and Budget. Standards for Delineating Metropolitan and Micropolitan Statistical Areas. Fed. Regist. 2010, 75. Available online: https:/ / www.federalregister.gov/documents /2010/06/28/2010-15605/2010-standards-for-delineatingmetropolitan-and-micropolitan-statistical-areas (accessed on 1 December 2020).

18. European Commission/Eurostat. Methodological Manual on Territorial Typologies; 2018 Edition; Publications Office of the European Union: Luxembourg, 2019; Available online: https: / / ec.europa.eu/eurostat/documents /3859598/9507230/KS-GQ-18-008-ENN.pdf/a275fd66-b56b-4ace-8666-f39754ede66b?t=1573550953000 (accessed on 1 December 2020).

19. Ahmad, E. Multilevel responses to risks, shocks, and pandemics: Lessons from the evolving Chinese governance model. J. Chin. Gov. 2020. [CrossRef] 
20. U.S. Institute of Medicine. Committee on Assuring the Health of the Public in the 21st Century. In The Future of the Public's Health in the 21st Century; National Academies Press: Washington DC, USA, 2002.

21. Plough, A. Understanding the financing and functions of metropolitan health departments: A key to improved public health response. J. Public Health Manag. Pract. 2004, 10, 421-427. [CrossRef] [PubMed]

22. Rudolph, L.; Caplan, J.; Ben-Moshe, K.; Dillon, L. Health in All Policies: A Guide for State and Local Governments; American Public Health Association and Public Health Institute: Washington, DC, USA, 2013; Available online: https://www.apha.org/ \{\}/ media/files/pdf/factsheets/health_inall_policies_guide_169pages.ashx (accessed on 4 October 2020).

23. Code of the Metropolitan Service District. Available online: https://www.oregonmetro.gov/sites/default/files/2017/09/20 / complete-Metro-Code-updated-20170920.pdf (accessed on 10 December 2020).

24. South Coast Air Quality Management District (AQMD). Governing Board. 2020. Available online: http://www.aqmd.gov/nav/ about/governing-board (accessed on 1 October 2020).

25. Keil, R.; Ali, H. Governing the Sick City: Urban Governance in the Age of Emerging Infectious Disease. Antipode 2007, $39,864-872$. [CrossRef] [PubMed]

26. Brenner, N. New State Spaces: Urban Governance and the Rescaling of Statehood; Oxford University Press: Oxford, UK, 2004.

27. U.S. International Air Passenger and Freight Statistics for June 2019, Office of the Assistant Secretary for Aviation and International Affairs, U.S. Department of Transportation, Released February 2020. Available online: https://www.transportation.gov/ administrations/office-policy/us-international-air-passenger-and-freight-statistics-report-first (accessed on 1 July 2020).

28. Angel, S.; Blei, A.M. COVID-19 Thrives in Larger Cities, Not Denser Ones, Working Paper, 4 August 2020. Available online: https:/ / papers.ssrn.com/sol3/papers.cfm?abstract_id=3672321 (accessed on 1 November 2020).

29. Angel, S.; Blei, A.M. The spatial structure of American cities: The great majority of workplaces are no longer in CBDs, employment sub-centers, or live-work communities. Cities 2016, 51, 21-35. [CrossRef]

30. U.S. Census Bureau. LEHD Origin-Destination Employment Statistics (2002-2017); U.S. Census Bureau, Longitudinal-Employer Household Dynamics Program: Washington, DC, USA, 2017; LODES 7.4. Available online: https:/ / onthemap.ces.census.gov (accessed on 30 October 2020).

31. Franch-Pardo, I.; Napoletano, B.M.; Rosete-Verges, F.; Lawal, B. Spatial Analysis and GIS in the Study of COVID-19. A Review. Sci. Total Environ. 2020, 739. [CrossRef] [PubMed]

32. Hoeven, E. Newsom vs. Orange County-Again, Cal Matters, 15 July 2020. Available online: https:/ / calmatters.org/newsletters / whatmatters/2020/07/orange-county-school-reopening-gavin-newsom/ (accessed on 15 September 2020).

33. Bizjak, T.; Ahumada, R. California Regulators Descend on Yuba and Sutter as Coronavirus Battle with Newsom Heats Up, Sacramento Bee. Available online: https:/ / www.sacbee.com/news/business/article242549156.html (accessed on 6 May 2020).

34. Rodwin, V.G.; Gusmano, M.G. The World Cities Project: Rationale, Organization, and Design for Comparison of Megacity Health Systems. J. Urban Health 2002, 79, 445-463. [CrossRef] [PubMed] 